\title{
QUALIDADE INSTITUCIONAL E DESENVOLVIMENTO SOCIOECONÔMICO DOS MUNICÍPIOS DO TERRITÓRIO DE IDENTIDADE DO SISAL, BAHIA
}

Ricardo Candéa Sá Barreto ${ }^{1}$; Leonardo Batista Duarte ${ }^{2}$; Adrielle Victória Soares Alves ${ }^{3}$.

\begin{abstract}
Resumo
O presente estudo teve como objetivo averiguar a qualidade institucional e a relação com o desenvolvimento socioeconômico dos municípios do Território de Identidade do Sisal da Bahia. Para isso, mensurou-se o Índice de Qualidade Institucional Municipal (IQIM) do Ministério do Planejamento do Brasil para o ano 2012. Após, através de testes de correlação, causalidade e pelo modelo de dados em painel, analisou-se a existência da correlação do IQIM com outros índices, como GINI, Desenvolvimento Humano (IDH), Produto Interno Bruto (PIB) e PIB per capita de 2000 e 2012. Os resultados do IQIM apontaram que os municípios do sisal apresentam baixo grau de participação, nível mediano de capacidade financeira e alto nível gerencial. Os resultados demonstram, também que o indicador está associado positivamente com variáveis socioeconômicas. Infere-se uma relação positiva entre qualidade institucional e desenvolvimento socioeconômico, mas não com distribuição de renda.
\end{abstract}

Palavras-chave: Análise institucional; Desenvolvimento Local; Território de Identidade; Indicadores de Desenvolvimento.

\footnotetext{
${ }^{1}$ Doutor em Economia pela Universidade Federal de Viçosa - MG e analista da DJU/CAGECE Diretoria Jurídica da Companhia de Água e Esgoto do Ceará. E-mail: ricardocandea@yahoo.com.br ${ }^{2}$ Mestre em Economia Regional e Políticas Públicas pela Universidade Estadual de Santa Cruz - UESC. Urbanista pela Universidade do Estado da Bahia - UNEB. E-mail: leo_duartee@ hotmail.com

${ }^{3}$ Doutoranda em Administração pela Universidade Federal da Bahia (UFBA); Mestra em Economia Regional e Políticas Públicas e Graduada em Administração pela Universidade Estadual de Santa Cruz UESC. E-mail: adriellevictoria@gmail.com
} 


\title{
INSTITUTIONAL QUALITY AND SOCIOECONOMIC DEVELOPMENT OF THE CITIES OF THE SISAL, BAHIA TERRITORY
}

\begin{abstract}
This study aimed to investigate the institutional quality and the relationship with the socioeconomic development of the municipalities of Bahia Sisal Territory. For that, it was measured the Municipal Institutional Quality Index (MIQI) of the Ministry of Planning of Brazil for the year 2012. The correlation between MIQI and other indexes, such as GINI, Human Development (HDI), Gross Domestic Product (GDP), and GDP per capita of MIQI, was analyzed through correlation, causality and panel data models, 2000 and 2012. The MIQI results showed that the sisal municipalities have a low level of participation, average level of financial capability and high management level. In addition, there is linear correlation between relevant MIQI and GDP, unlike the GINI. Such analyzes infer a positive relationship between institutional quality and richness, but not with income distribution. The results also show that the indicator is positively associated with socioeconomic variables. A positive relationship between institutional quality and socioeconomic development is inferred, but not with income distribution.
\end{abstract}

Keywords: Institutional analysis; Local Development; Territory Identity; Development Indicators.

JEL: O18, O21, R58

\section{Introdução}

A qualidade institucional na gestão municipal é um tema que tem ganho espaço nas investigações da literatura empírica sobre crescimento e desenvolvimento econômico nacional. De acordo com Santana e Barreto (2016, 2017), o país apresenta elevados níveis de desigualdade regionais, comparativamente às nações desenvolvidas, o que levanta a hipótese de intensa heterogeneidade institucional entre os municípios brasileiros. Ou seja, as diversidades intermunicipais podem estar associadas aos diferentes ambientes institucionais presentes em cada município. Autores como Oliveira; Menezes-Filho; Komatsu (2018), Bastos; Oliveira; Ribeiro (2018), Ribeiro; Bastos; Oliveira (2017), e Santana e Barreto $(2016,2017)$ defendem que as discussões sobre as instituições quase sempre estão direcionadas ao papel que exercem no processo de desenvolvimento econômico e nas relações sociais, econômicas e políticas de uma localidade. 
No contexto internacional, considerações acerca das relações envolvendo instituições e desenvolvimento econômico podem ser encontradas nos estudos de Boisier (2000) e Acemoglu, Johnson e Robinson (2001). Boisier (2000) pressupõe que, além das instituições, existem outros fatores intangíveis considerados endógenos, como o capital social, capital humano, capital cívico e outros não econômicos, que dotam a região de capacidade de atingir o desenvolvimento sustentável, ou seja, equilibrado e a longo prazo. Em relação ao trabalho de Acemoglu, Johnson e Robinson (2001), foi verificado efeito das instituições nas condições do ambiente sobre a performance econômica. Como resultado, averiguaram efeitos significantes e que de fato existe uma relação de causalidade envolvendo instituições e desenvolvimento.

Autores como Knack e Keefer (1995), Hall e Jones (1999) e Acemoglu et al. (2001) utilizaram os indicadores fornecidos pelos avaliadores de risco país a potenciais investidores estrangeiros, para entenderem o impacto dos direitos de propriedade sobre o investimento ou a produtividade da mão de obra e, consequentemente, sobre o crescimento econômico dos países no longo prazo. Empregando variados instrumentos para o controle da endogeneidade, todos chegaram à conclusão de que o desempenho econômico de longo prazo é determinado pelas "instituições boas", ou seja, aquelas que protegem os direitos de propriedade. De um modo geral, o que predomina na literatura cross-country é uma relação de causa e consequência entre instituições e desenvolvimento econômico. Como observam Pande e Udry (2005), os trabalhos que exploraram o perfil institucional dos países encontraram uma relação causal entre as boas instituições e o crescimento econômico de longo prazo, de modo que a qualidade do ambiente institucional se colocou como um determinante do desempenho econômico dos países.

No Brasil, mais recentemente, alguns autores têm investigado a relação do desenvolvimento econômico com o capital humano, social e institucional na perspectiva endógena. A pesquisa de Haddad (2004), por exemplo, analisou as disparidades existentes nos municípios do Estado de Minas Gerais com base em 10 (dez) indicadores ${ }^{4}$ de desenvolvimento econômico, social e político-institucional. $\mathrm{O}$ autor considerou que os municípios que apresentaram baixo potencial endógeno de desenvolvimento social, humano e institucional foram classificados como municípios economicamente deprimidos. Já Piacenti (2009), alicerçado na Teoria do Desenvolvimento Endógeno, analisou a potencialidade dos municípios do Estado do Paraná com base em três dimensões ${ }^{5}$ : econômica, social e institucional. Similarmente ao trabalho de Haddad

\footnotetext{
${ }^{4}$ Indicadores do trabalho de Haddad (2004): Índice de Desenvolvimento Humano Municipal - IDHM; IDHM Renda; IDHM Longevidade; IDHM Educação; PIB per capita; Índice de Qualidade Institucional Municipal - IQIM; Índice do Potencial de Desenvolvimento do Município - IPDM; Índice de Exclusão Social - IES; Índice de Pobreza - IP; e Índice de Desigualdade - ID.

${ }^{5}$ Dimensão Econômica: Indicador do Nível de Crescimento - INC; Indicador do Ritmo de Crescimento IRC; Indicador do Potencial de Desenvolvimento Municipal - IPDM. Dimensão Social: Índice de
} 
(2004), os resultados mostraram que os municípios também considerados deprimidos tinham baixa potencialidade de capital social e capital humano.

Complementarmente, ao realizarem um estudo para todos os municípios brasileiros, de uma forma geral, Neto e Nakabashi (2011) e Neto, Nakabashi e Sampaio (2013), utilizando o IQIM como proxy para instituições, analisaram os impactos destas e do capital humano no investimento líquido e no capital físico por trabalho, respectivamente. Os trabalhos chegaram à conclusão de que o nível de capital humano e a qualidade institucional se relacionam positivamente com o investimento e o nível de capital físico, uma vez que municípios com maiores níveis de capital humano e melhores arranjos institucionais tendem a ter um produto marginal do capital físico maior.

Também usando o IQIM, Leivas et al. (2015) buscaram verificar a importância das variáveis espaciais para o desempenho econômico dos municípios brasileiros. Controlando a dependência espacial através do modelo espacial de Durbin2 e considerando o período de 2000 a 2010, demonstraram que a qualidade institucional dos vizinhos influencia o desempenho econômico dos municípios. O estudo chama atenção para a importância que o planejamento institucional dos municípios tem para a performance econômica dos mesmos, além de sugerir que deve haver uma atualização dos indicadores que mensuram a qualidade institucional, dado a transformação estrutural ocorrida nesses entes federados desde o início do século XXI.

Santana e Barreto (2016), além de utilizarem o IQIM, dão uma contribuição à literatura ao atualizá-lo, com os dados do IBGE para o ano de 2010. Desta forma, os autores são capazes de não só detectarem o impacto das instituições no crescimento econômico, mas também tentarem identificar se houve algumas transformações institucionais nos municípios, e qual o impacto deste movimento para seus produtos. Estes verificaram que a influência da qualidade institucional sobre a renda é maior do que o contrário, apesar de ambas as direções apresentarem coeficientes positivos ao modelo.

Ainda na literatura nacional mais aplicada, Pereira, Nakabashi e Salvato (2012) procuraram mensurar a qualidade das instituições dos municípios paranaenses e avaliar o efeito que elas exercem sobre seus respectivos níveis de renda. A análise empírica mostrou que os indicadores de qualidade institucional empregados são significativos para explicar diferenças no PIB per capita entre os municípios do estado do Paraná.

Longevidade Municipal- ILM; Índice de Educação - IE. Dimensão Institucional: Índice de Qualidade Institucional Municipal - IQIM 
Os trabalhos referidos abrem a possibilidade de se estudar a relação que as instituições exercem sobre o desenvolvimento regional. Considerando a heterogeneidade das regiões brasileiras, a situação institucional, econômica e social varia conforme os diferentes territórios existentes dentro de cada estado. A Bahia, por exemplo, entre os estados brasileiros, detém o $6^{\circ}$ (sexto) maior Produto Interno Bruto do país, $\mathrm{R} \$$ 154.340.458 milhões no ano de 2010. Dentro do estado da Bahia, o Território de Identidade do Sisal ocupa a $13^{\mathrm{a}}$ posição na classificação do Produto Interno Bruto (PIB), com R \$ 2.658,77 milhões em 2010, representando apenas 1,72\% do PIB total do estado. O Sisal baiano é considerado uma região com baixo nível de desenvolvimento socioeconômico (CONAB, 2013).

Acredita-se, com base na teoria de North (1990), que a melhoria no desempenho institucional tem consequências econômicas importantes. Além disso, o aperfeiçoamento das instituições pode melhorar a distribuição de renda. Tais fatores justificam a importância desta pesquisa, além do ineditismo de seu teor. Nacionalmente, existem alguns estudos relacionados a pequenos municípios, mas pouquíssimos trabalhos acadêmicos que abordem, de alguma forma, a questão das capacidades institucionais para os municípios baianos foram encontrados, nenhum com caráter quantitativo.

Diante desse contexto, a pergunta a ser respondida é a seguinte: É possível afirmar que o nível de desenvolvimento dos municípios do Território de Identidade do Sisal é explicado pelo nível de capacidade de suas instituições? Partindo deste ponto, o presente estudo buscou mensurar a qualidade institucional dos municípios sisaleiros baianos e analisar sua relação com alguns de seus indicadores socioeconômicos. Assim, o presente trabalho buscou mostrar quais são as carências quanto as capacidades institucionais dos municípios do território de identidade do sisal e que tem como base econômica predominante a agropecuária.

Metodologicamente, dentro desse objetivo, foram propostas, especificadamente, a mensuração do Indicador de Qualidade Institucional dos Municípios do Sisal (IQIM) para o ano de 2012, utilizado dentro do modelo econométrico de dados em painel como variável representativa da qualidade institucional. A construção dessa variável permitiu, ainda, verificar os diferenciais no comportamento do IQIM dos anos de 2000, já existente, e de 2012. Por fim, analisar as desigualdades socioeconômicas entre os municípios através de uma perspectiva institucionalista.

O presente trabalho está estruturado em seções, sendo a primeira está introdução. A segunda seção corresponde à caracterização socioeconômica dos municípios do Território de Identidade do Sisal da Bahia. A terceira seção apresenta a metodologia empregada na análise da qualidade institucional e da correlação das variáveis. A quarta seção é referente aos resultados e discussões. E por fim, a quinta seção é reservada às considerações finais do trabalho. 


\section{Caracterização Socioeconômica dos Municípios do Território de dentidade do Sisal, Bahia}

Situado na mesorregião nordeste do estado da Bahia, o Território de Identidade do Sisal, área de estudo desta pesquisa, compreende 20 municípios: Araci, Barrocas, Biritinga, Candeal, Cansanção, Conceição do Coité, Ichu, Itiúba, Lamarão, Monte Santo, Nordestina, Queimadas, Quijingue, Retirolândia, Santaluz, São Domingos, Serrinha, Teofilândia, Tucano e Valente, conforme mapa da Figura 1.

A denominação do território é resultante da característica principal da região que é o intenso cultivo e produção do sisal, fibra dura natural mais plantada no mundo. $\mathrm{O}$ Brasil atualmente é o maior produtor mundial de sisal, com cerca de 48,4\% da produção mundial, na frente de países como Tanzânia e China. Nacionalmente, sua concentração produtiva está no semiárido nordestino, com destaque para a Bahia. No ano de 2012, a produção nacional de sisal foi de $55 \mathrm{mil} / \mathrm{t}$ e a produção baiana, de $52,5 \mathrm{mil} / \mathrm{t}$, o que corresponde a $95 \%$ da produção nacional (CONAB, 2013).

Historicamente, a atividade sisaleira é a base da economia dos 20 municípios do território do sertão da Bahia. Porém, nos últimos dez anos, a região do sisal apresentou queda de mais de $50 \%$ da produção, decorrente de fatores climáticos como secas e, consequentemente, proliferação de fungos e pragas nas plantações, como a podridão vermelha do tronco do sisal, alto nível de pobreza e falta de recursos dos produtores para o aproveitamento total das plantações e para a subsistência, além dos baixos preços no mercado nacional e internacional. Assim, a situação socioeconômica dos municípios é crítica, visto que a principal fonte de renda e de subsistência dos cidadãos é proveniente da atividade sisaleira (CODES, 2010).

Os mapas da Figura 2 mostram os valores em quantis dos PIBs a preços correntes de 2000 e 2012 dos municípios do Território de Identidade do Sisal. Observa-se nos dois períodos analisados que os municípios de Conceição do Coité e Serrinha aparentam melhores níveis de riqueza em relação aos demais. De certa forma, se analisarmos o Território como um todo, percebe-se também que existe um padrão entre melhores e piores, uma vez que os municípios mais atrasados em 2000 continuaram com PIB relativamente mais baixo em 2012, sendo a única exceção o município de Barreiras, que ainda não existia até o ano de 2000. 
Figura 1 - Mapa de localização dos municípios do Território de identidade do Sisal da Bahia - Lei ${ }^{\circ} 13.360$ de 29 de junho de $2015^{6}$

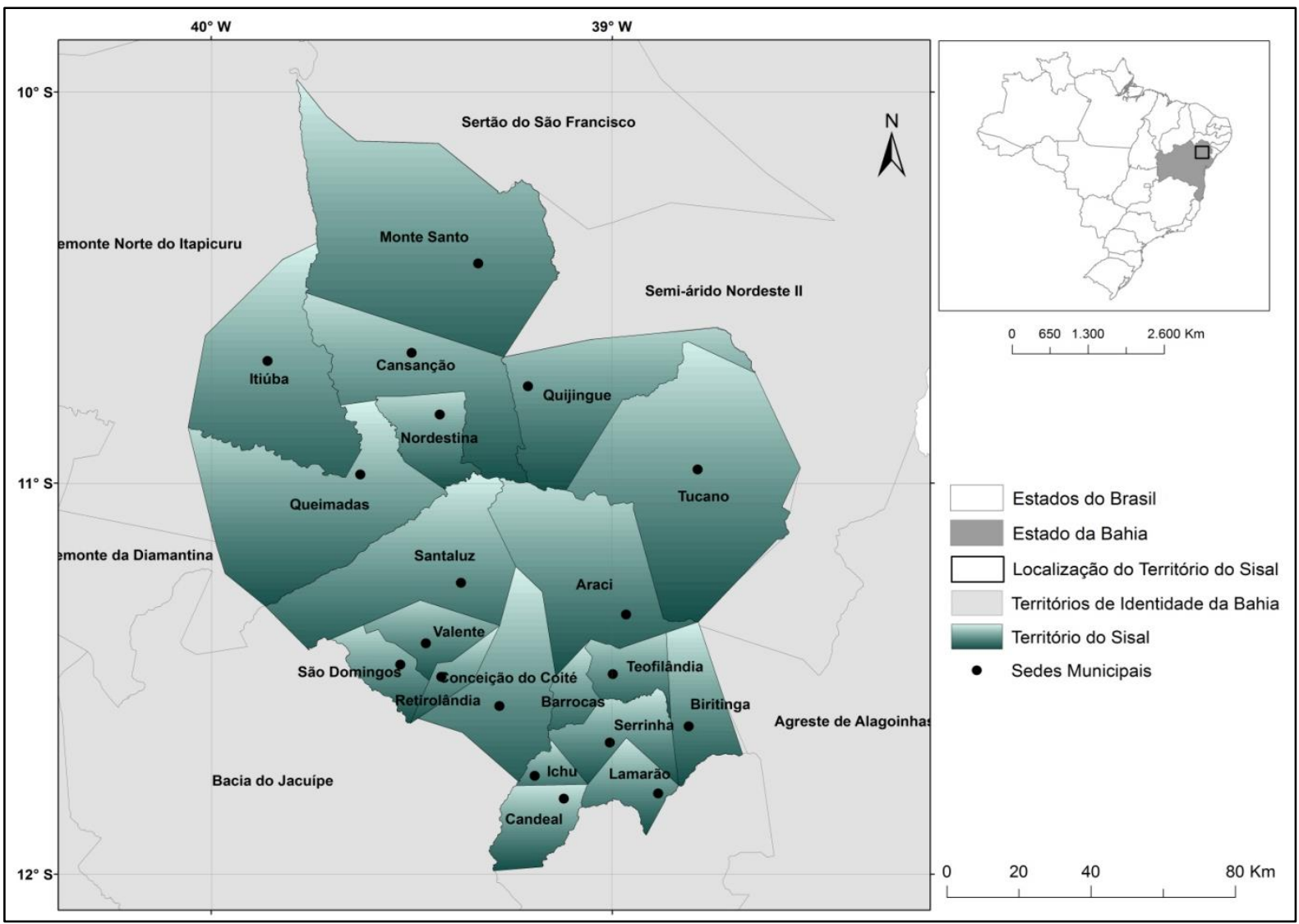

Fonte: Elaborado pelos autores, com base em CONDER (2010).

${ }^{6}$ Disponível on-line em:

http://www.sei.ba.gov.br/index.php?option=com_content\&view=category\&id=1550\&Itemid=101 .

Consulta realizada em 10.12.18. Municípios de: Araci, Barrocas, Biritinga, Candeal, Cansanção, Conceição do Coité, Ichu, Itiúba, Lamarão, Monte Santo, Nordestina, Queimadas, Quijingue, Retirolândia, Santaluz, São Domingos, Serrinha, Teofilândia, Tucano e Valente. 
Figura 2 - PIB a preços correntes (R\$ 1000) dos municípios sisaleiros, 2000 - 2012

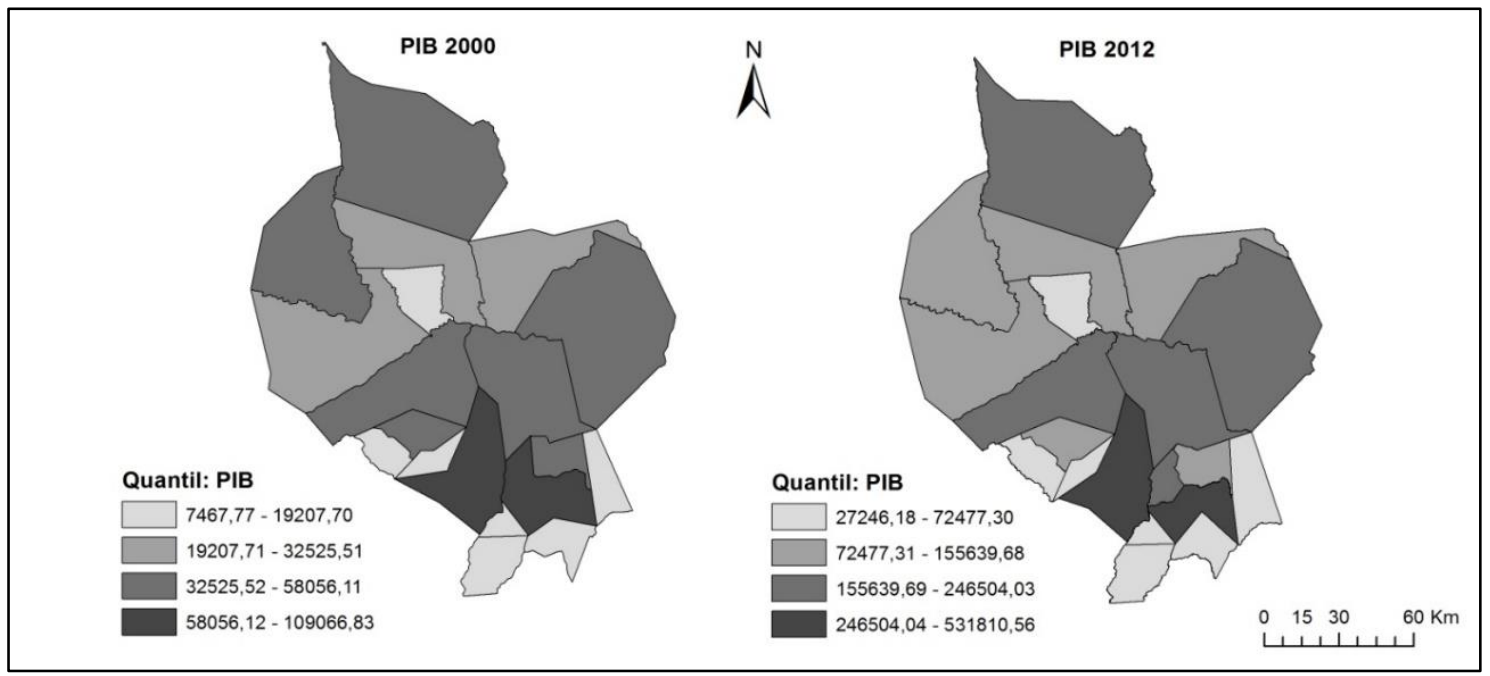

Fonte: Elaborado pelos autores com base em IBGE (2015).

Por outro lado, quando se observam os valores do PIB per capita destes municípios, os resultados apontam para outra disparidade no quadro econômico. Quando comparado com o ano de 2000, percebe-se uma piora na distribuição de renda entre os municípios sisaleiros. O município de Barreiras apresenta o maior PIB per capita da região, R\$ 14.424,64 no ano de 2012, muito superior aos outros municípios (Figura 3).

Figura 3 - PIB per capita (R\$ 1,00) dos municípios sisaleiros, 2000 -2012

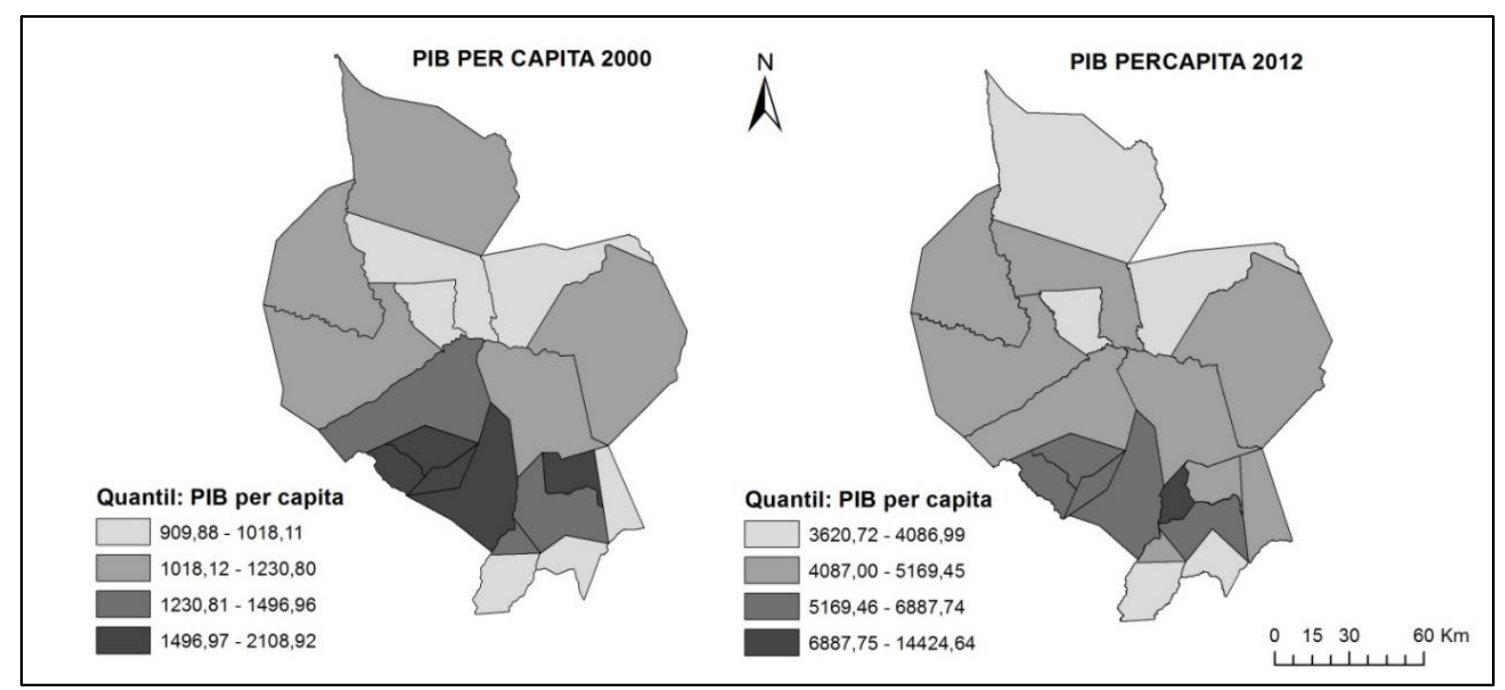

Fonte: Elaborado pelos autores com base em IBGE (2015). 
Embora os valores do PIB per capita tenham aumentado em relação ao ano de 2000 para todos os 20 municípios do Sisal, as condições de pobreza permanecem como situação crítica na região. Os mapas da Figura 4 mostram que o índice de Gini da renda domiciliar per capitados municípios sisaleiros está longe de ser considerado entre os melhores da Bahia, muito menos do Brasil, pois o melhor valor de Gini ficou em torno de 0,42 em 2000 e de 0,44 em 2010.

Figura 4 - IDH dos municípios sisaleiros, 2000 - 2010

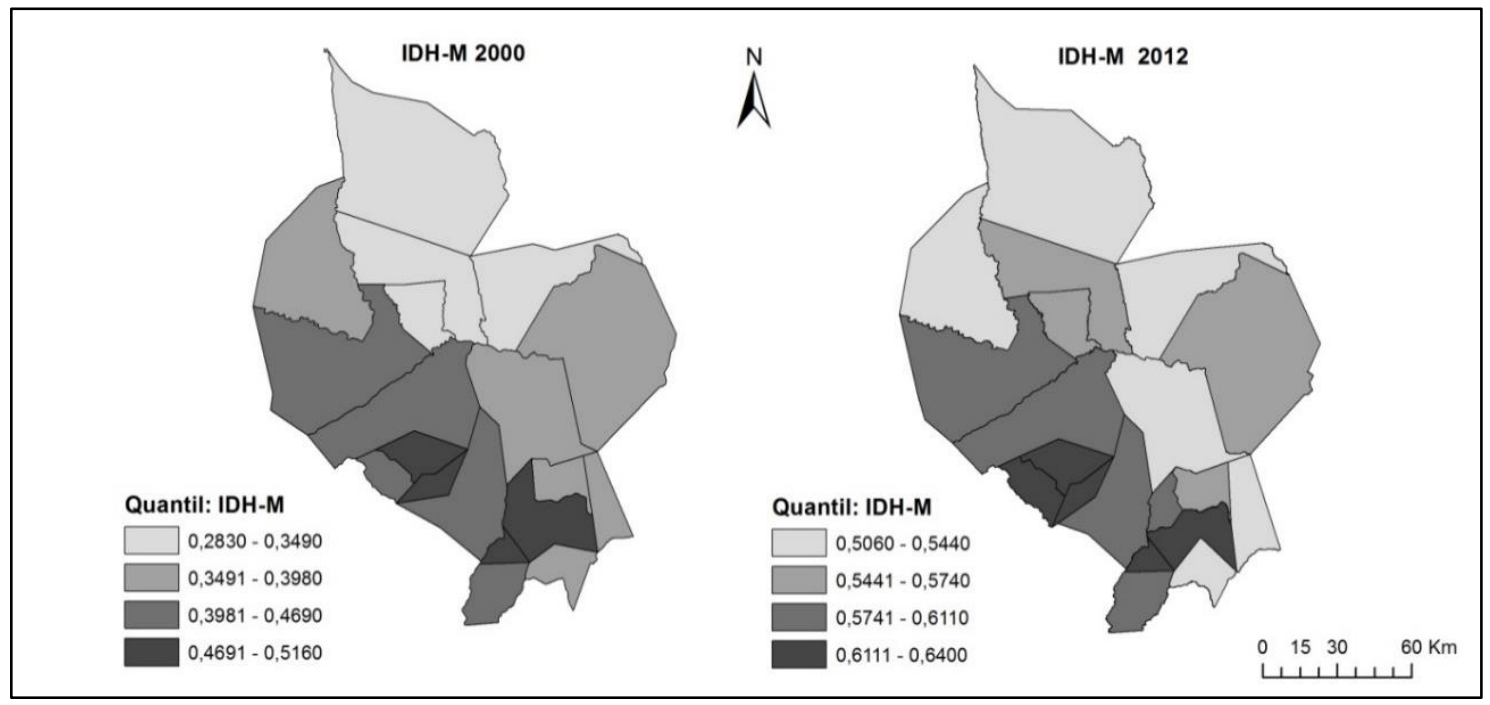

Fonte: Elaborado pelos autores com base em IBGE/DATASUS (2015)

Analisando a condição de bem-estar destes municípios, percebe-se uma melhoria do Índice de Desenvolvimento Humano Municipal (IDH-M), comparando o ano de 2000 com 2010. Mas é importante ressaltar que tal melhoria só é significativa analisando sua evolução em relação ao período anterior, uma vez que o melhor IDH-M do Sisal no ano de 2000 era de 0,51 e em 2010, de 0,64, ambos os valores considerados medianos em relação aos melhores do Brasil. Destaque para Conceição do Coité, Ichu, Serrinha e Valente, que apresentaram melhores IDH-M no ano de 2000. Estes mesmos municípios continuam apresentando melhores condições no ano de 2010, acompanhados pelos municípios de Barreiras e São Domingos.

No geral, os indicadores econômicos não refletem melhorias nas condições de bem-estar nos municípios sisaleiros, exceto em alguns casos isolados. A próxima seção é destinada aos procedimentos metodológicos desta pesquisa. 
Figura 5 - índice Gini de renda domiciliar per capita dos municípios sisaleiros, 2000 2012

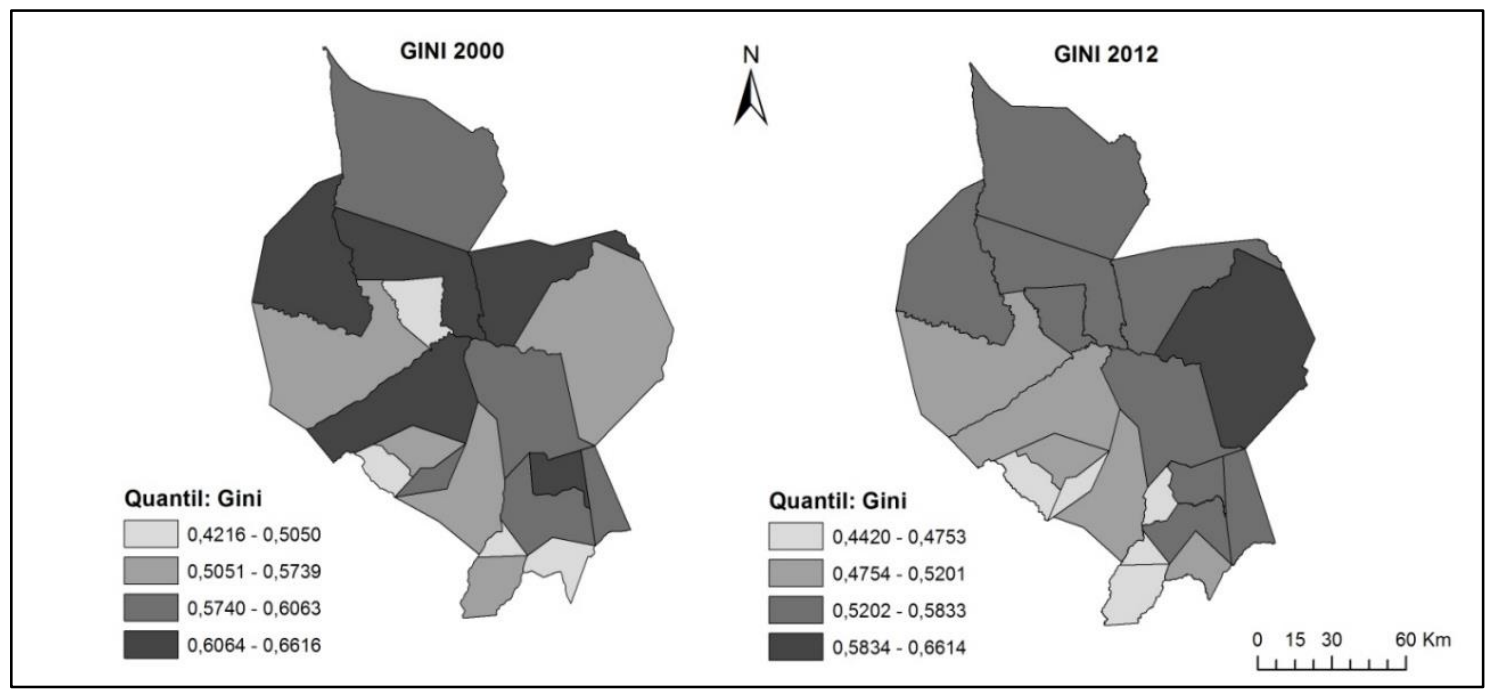

Fonte: Elaborado pelos autores com base PNUD (2015).

\section{Metodologia}

O presente estudo tem caráter quantitativo com base em dados secundários e apoio no modelo estruturado por Haddad (2004) e Piacenti (2009, 2012). Foram utilizados, em especial, o Índice de Qualidade Institucional Municipal (IQIM) como proxy para mensurar a capacidade institucional dos municípios do Território de Identidade do Sisal e o coeficiente de Pearson para verificar possíveis correlações entre qualidade institucional e desenvolvimento socioeconômico.

Conceitualmente, Hall e Jones (1999) a qualidade das instituições surge como uma incógnita crucial para explicar a grande disparidade do desempenho econômico entre os países. E nesta abordagem a qualidade institucional é a infraestrutura social que corresponde ao conjunto de políticas públicas que promovem incentivos que encorajam atividades produtivas e acumulação de conhecimentos e habilidades necessários ao desenvolvimento de novos negócios e técnicas produtivas, aumentando assim, a probabilidade das firmas se perpetuarem em um mercado de competição. Considerando o crescente interesse, tanto acadêmico como de gestão pública, em temas relacionados às instituições e a qualidade institucional, o Consórcio Monitor/Boucinhas e Campos elaborou, a pedido do Ministério do Planejamento, Orçamento e Gestão - MPOG o Índice de Qualidade Institucional Municipal - IQIM. Este índice procura mensurar a capacidade de gestão e estrutura administrativa dos municípios ${ }^{7}$.

${ }^{7}$ O IQIM foi elaborado para projeto de Atualização dos Eixos Nacionais de Integração e Desenvolvimento utilizando uma amostra de 5.507 municípios brasileiros existentes no período de 1997-2000. Por conta do 
Em consonância com os objetivos deste estudo, o IQIM foi calculado para os 20 municípios do Território de Identidade do Sisal referentes ao ano de 2012. Pela dificuldade de obter todos esses dados na atualidade, não foi possível obedecer à mesma metodologia adotada para o IQIM do Sisal. Sendo assim, adotou-se o uso de outras variáveis no modelo. Para compreender o processo utilizado da análise da capacidade institucional dos municípios do Território de Identidade do Sisal, é importante explicar a forma como o IQIM foi calculado.

\section{1. Índice de Qualidade Institucional Municipal (IQIM)}

O IQIM ${ }^{8}$ é dividido em três conjuntos de subíndices, cada um com peso igual a 33,33\%, sendo eles: Grau de Participação, Capacidade Financeira e Capacidade Gerencial. Para a construção de cada subíndice, atribuiu-se nota de 1 a 6 para cada município, conforme equação a seguir (01):

$$
M I=\left[\frac{X-\text { menor } X}{\text { maior } X-\text { menor } X} \times 5\right]+1
$$

Em que $X$ é o dado do município e o menor valor é dado para o município que não obteve informação disponível. Assim, o município que obtiver nota 6 , consequentemente, terá uma melhor capacidade institucional. A Tabela 1 resume a construção de cada conjunto de subindicadores.

Tabela 1 - Componentes do Índice de Qualidade Institucional Municipal (IQIM)

\begin{tabular}{|c|c|c|c|c|}
\hline Índice & Subíndices & Microíndices & & Fonte \\
\hline \multirow{10}{*}{$\begin{array}{l}\text { IQIM } \\
(100 \%)\end{array}$} & \multirow{3}{*}{$\begin{array}{l}\text { Grau de Participação } \\
(33,3 \%)\end{array}$} & Existência de Conselhos & $4,00 \%$ & IBGE (2012) \\
\hline & & Conselhos Instalados & $4,00 \%$ & Idem \\
\hline & & Características dos Conselhos & $25,33 \%$ & Idem \\
\hline & \multirow{3}{*}{$\begin{array}{l}\text { Capacidade Financeira } \\
(33,3 \%)\end{array}$} & Existência de Consórcios & $11,11 \%$ & IBGE (2011) \\
\hline & & Receita Corrente X Dívida & $11,11 \%$ & TCM (2012) \\
\hline & & Poupança Real per capita & $11,11 \%$ & STN (2012) \\
\hline & \multirow{4}{*}{$\begin{array}{c}\text { Capacidade Gerencial } \\
(33,3 \%)\end{array}$} & Existência de Cadastro Imobiliário & $8,33 \%$ & IBGE (2012) \\
\hline & & Cobrança de IPTU* & $8,33 \%$ & Idem \\
\hline & & Instrumentos de Gestão & $8,33 \%$ & Idem \\
\hline & & Instrumentos de Planejamento & $8,33 \%$ & Idem \\
\hline
\end{tabular}

Fonte: Adaptado de Consórcio Monitor/Boucinhas e Campos (apud Haddad, 2004, e Piacenti, 2012). Nota: * Imposto sobre Propriedade Predial e Territorial Urbana.

número de variáveis envolvidas no cálculo do IQIM este é um índice de computação não trivial, talvez por conta disto até hoje só tenha sido estimado para todos os municípios brasileiros apenas uma vez.

${ }^{8}$ Para mais detalhes consultar Haddad (2004) e Piacenti (2009, 2012). 
O subíndice Grau de Participação é calculado pelo número de Conselhos Municipais instalados que efetivamente estavam em funcionamento ${ }^{9}$. Além de considerar sua existência e funcionamento, são verificadas e também as características ${ }^{10}$ de cada conselho. Para este cálculo, foram considerados os conselhos com as seguintes características: Conselho Municipal de Política Urbana, Desenvolvimento Urbano, da Cidade ou similar, Conselho Municipal de Habitação, Conselho Municipal de Transporte, Conselho Municipal de Meio Ambiente e Conselho Municipal de Cultura. É importante ressaltar que tanto os conselhos Tutelar, da Saúde e também de Educação não foram incluídos no modelo porque são de obrigatoriedade para todos os municípios, segundo a lei ordinária (HADDAD, 2004; PIACENTI, 2012).

O subíndice Capacidade Financeira dos municípios pode ser calculado por três microíndices com peso de $11,11 \%$. O primeiro microíndice é o número de consórcios ${ }^{11}$ criados, dos quais o município participa. Para seu cálculo, foram considerados os consórcios públicos intermunicipais com peso de $6,11 \%$ e os consórcios públicos com Estado e União, cada um com pesos iguais à 2,5\%. Considera-se que os consórcios apenas entre municípios têm um maior respaldo, por isso uma pontuação maior. $\mathrm{O}$ outro microíndice é a relação entre as receitas arrecadadas e as despesas realizadas $(\mathrm{REC} / \mathrm{DESP})^{12}$. Este microíndice serve para verificar se o dado município tem déficit ou superávit orçamentário. Já o terceiro microíndice da Capacidade Financeira é a Poupança Real per capita (PRpc), obtida pela seguinte expressão (PIACENTI, 2012):

$$
P R_{p c}=\frac{R T-O C-A B-A M-J E}{P O P}
$$

Em que $P R_{P C}$ representa a poupança real per capita; $R T$, a Receita Total Líquida de Despesas Correntes; $O C$, as Operações de Crédito; $A B$, a Alienação de Bens; $A M$, as Amortizações; JE, os Juros e Encargos da Dívida; e POP representa a população total. Assim, com base nesta expressão, foi calculado o valor da $P R_{p c}$ para cada município e atribuída uma nota em função do valor obtido referente ao salário mínimo ${ }^{13}$.

O subíndice Capacidade Gerencial é calculado com base em quatro microíndices, sendo o tipo de resposta para esta análise sim ou não, e a pontuação, de acordo com a quantidade de respostas positivas. Sendo assim, o primeiro microíndice verificou a

\footnotetext{
${ }^{9}$ Foram considerados os conselhos que fizeram reunião nos últimos 12 meses.

${ }^{10}$ Foram considerados cinco tipos de caráter dos conselhos: paritário, consultivo, deliberativo, normativo e fiscalizador. Esse indicador foi agrupado e passou a ter um peso maior, totalizando $25,33 \%$.

${ }^{11}$ Desta forma, nestes três segmentos de consórcios, diversas áreas foram incluídas, tais como: educação, saúde, assistência e desenvolvimento social, emprego, turismo, cultura, habitação, meio ambiente, transporte, desenvolvimento urbano e saneamento básico.

${ }^{12}$ Para o cálculo deste microíndice, o valor de $11,11 \%$ é dado para o município que tem a relação de Rec/Desp igual ou maior que 1 .

13 O Salário Mínimo - S.M. no ano de 2012 era de R\$ 622,00 (Portal Brasil, 2014).
} 
existência de cadastro imobiliário. Assim foram consideradas quatro variáveis: existência de cadastro imobiliário, cadastro imobiliário informatizado, existência de planta genérica de valores e planta genérica de valores informatizada. O segundo microíndice verificou a Cobrança de Imposto Predial e Territorial Urbano (IPTU). Este microíndice pode ser obtido por duas variáveis: se o município cobra IPTU e o ano de publicação da lei que autoriza a cobrança do imposto. Caso o município faça a cobrança do IPTU, ele obterá um percentual de 5,33\%, e o restante será atribuído em função do ano de publicação da lei. O terceiro microíndice verificou a existência de instrumentos de gestão ${ }^{14}$ e o quarto, a existência dos instrumentos de planejamento ${ }^{15}$ (PIACENTI, 2012).

O nível de condição para cada um dos subíndices será apresentado de acordo com a distribuição percentual em relação à média do IQIM do Território de Identidade do Sisal (Tabela 2).

Tabela 2 - Faixas percentuais para o modelo utilizado

\begin{tabular}{ccccc}
\hline \multicolumn{1}{c}{ Subíndice } & Baixo & Regular & Mediano & Alto \\
\hline Grau de Participação & $<8,33 \%$ & $8,33 \% \mathrm{a}<16,66 \%$ & $16,66 \% \mathrm{a}<24,99 \%$ & $>24,99 \%$ \\
Capacidade Financeira & $<8,33 \%$ & $8,33 \% \mathrm{a}<16,66 \%$ & $16,66 \% \mathrm{a}<24,99 \%$ & $>24,99 \%$ \\
Capacidade Gerencial & $<8,33 \%$ & $8,33 \% \mathrm{a}<16,66 \%$ & $16,66 \% \mathrm{a}<24,99 \%$ & $>24,99 \%$ \\
\hline
\end{tabular}

Fonte: Modelo adaptado do trabalho de Piacenti (2009).

\subsection{Coeficiente de Correlação de Pearson}

A representação do cálculo do coeficiente de correlação de $\operatorname{Person}{ }^{16}$ (amostral) entre as variáveis $\mathrm{X}$ e $\mathrm{Y}$ é a seguinte:

$$
r=\frac{\operatorname{cov}(x, y)}{\sqrt{\operatorname{var}(x) \operatorname{var}(y)}}
$$

\footnotetext{
${ }^{14}$ Foram considerados instrumentos de gestão: Lei de Parcelamento do Solo, Lei de Zoneamento ou Ocupação de Solo, Código de Obras, Código de Posturas e Lei de Contribuição de Melhoria.

${ }^{15}$ Foram considerados instrumentos de planejamento: Lei Orgânica, Plano Diretor e Plano Plurianual.

16 Desenvolvido por Karl Pearson, o coeficiente de correlação de Person é uma medida estatística/econométrica de associação bivariada do grau de relacionamento linear entre duas variáveis, que varia de -1 a 1 . O sinal indica o resultado positivo ou negativo da relação das variáveis, e o valor sugere a força da relação entre as variáveis. Portanto, uma correlação perfeita (-1 ou 1) indica que o escore de uma variável pode ser determinado exatamente ao se saber o escore da outra. Opostamente, uma correlação de valor zero indica que não há relação linear entre as variáveis. Vale frisar que não se deve confundir correlação com causalidade (causa e efeito). Mais informações em: Figueiredo Filho \& Silva Júnior (2009), Martins (2002) e Santini, Oliveira \& Pigatto (2010).
} 
A variação de r vai de -1 e 1, conforme interpretação do coeficiente de correlação de Person. Assim, quando $-1<\mathrm{r}<0$, a correlação linear é negativa; $0<\mathrm{r}<1$, a correlação linear é positiva; e $r \cong 0$, a correlação linear é nula, logo, as variáveis não estão correlacionadas. Na próxima seção, serão apresentados os resultados e as discussões deste estudo.

\subsection{Modelo de Regressão com Dados em Painel}

A metodologia implementada utilizará a técnica de dados em painel, particularmente, serão apresentadas as estimações por Mínimos Quadrados Ordinários (MQO) para dados em painel (pooled OLS), efeito fixo e efeitos aleatórios, além dos testes de robustezes para a escolha do melhor modelo econométrico.

Os modelos de regressão com dados em painel, são também chamados de dados combinados, por agregar uma combinação de séries temporais e de observações em corte transversal multiplicadas por T períodos de tempo. Nesse caso, há muito mais informação para se estudar o fenômeno e graus de liberdade adicionais. Pode-se destacar algumas vantagens dos dados em painel em relação ao uso específico do corte transversal ou das séries temporais (BALTAGI, 2001; HSIAO, 2003). Essa pode ser considerada como uma combinação entre dados de corte transversal e de séries temporais permitindo o controle da heterogeneidade presente nos indivíduos. Ou ainda, os dados em painel são capazes de identificar e mensurar efeitos que não são possíveis de serem detectados por meio da análise de dados em corte transversal ou de séries temporais isoladamente

Contudo, no modelo de dados em painel pode ocorrer problemas relacionados ao enviesamento de seleção, isto é, erros resultantes da seleção dos dados que não formem uma amostra aleatória. Dessa forma, questões como a auto-seletividade (amostras truncadas) e ausência de resposta ou atrito podem ser consideradas, o que podem ser considerados de efeitos não observados.

Para a modelagem dos efeitos não observados existem duas possibilidades: os efeitos fixos e os efeitos aleatórios. No modelo de efeitos fixos considera-se que o intercepto específico de cada indivíduo pode estar correlacionado com um ou mais regressores. Quanto ao modelo de efeitos aleatórios, pressupõe-se que o intercepto (aleatório) de uma unidade individual não estão correlacionados com as variáveis explicativas (WOOLDRIDGE, 2002). 
É importante destacar que, assumindo-se a suposição de que o efeito não observado seja aleatório, isso não significa dizer que o efeito aleatório seria a melhor de estimação a ser adotada. Nesse caso, ao considerar que as variáveis não são correlacionadas, o método de efeitos aleatórios é o mais apropriado. Por outro lado, se os efeitos não observados estão correlacionados com alguma variável explicativa, a estimação por efeitos fixos seria a mais apropriada. Para a seleção do método, será realizado o teste de Hausman, entre os testes de efeitos fixos e aleatórios, além de outros testes para a validação da escolha do melhor modelo.

Apesar do foco deste artigo, com a aplicação do modelo de dados em páinel, ser verificar a relação dos determinares para o ano de 2000 e 2012, bem como verificar quais variáveis são representativas para explicar a qualidade institucional nos municípios do Território de Identidade do Sisal-Bahia, ainda assim, aplicou-se o teste de causalidade de Granger com os dois pontos no tempo, 2000 e 2012 (ver Anexo I), embora esse teste só tenha sido possível elaborar com uma defasagem temporal. Considerando a limitação do banco de dados disponível, encontramos as seguintes relações de causalidade de Granger ${ }^{17}$ para justificar a escolha das variáveis, além da literatura empírica: o IQIM (qualidade institucional) não causa GINI (desigualdade); o GINI (desigualdade) não causa IQIM (qualidade institucional); o IQIM (qualidade institucional) causa a $P I B_{\text {per }}$ (renda per capita); a $P I B_{\text {per }}$ (renda per capita) causa (qualidade institucional); o IQIM (qualidade institucional) causa o IDHm (desenvolvimento social); o IDHm (desenvolvimento social) não causa o IQIM (qualidade institucional).

No presente trabalho, a análise da influência do IQIM sobre variáveis socioeconômica e vice-versa serão estimados, pelas equações 4, 5, 6 e 7:

$$
\begin{aligned}
& \ln \left(\text { IQIM }_{i t}\right)=\alpha_{1}+\beta_{1} \ln \left(\text { PIBper }_{i t}\right)+\beta_{2} \ln \left(\text { IDHm }_{i t}\right)+\beta_{3} \ln \left(\text { GINI }_{i t}\right)+\varepsilon_{i t} \\
& \ln \left(\text { PIBper }_{i t}\right)=\alpha_{2}+\beta_{4} \ln \left(\text { IQIM }_{i t}\right)+\beta_{5} \ln \left(I D H m_{i t}\right)+\beta_{6} \ln \left(\text { GINI }_{i t}\right)+\varepsilon_{i t} \\
& \ln \left(\text { IDHm }_{i t}\right)=\alpha_{3}+\beta_{7} \ln \left(\text { PIBper }_{i t}\right)+\beta_{8} \ln \left(I Q I M_{i t}\right)+\beta_{9} \ln \left(\text { GINI I }_{i t}\right)+\varepsilon_{i t} \\
& \ln \left(\text { GINI }_{i t}\right)=\alpha_{4} \beta_{10} \ln \left(\text { PIBper }_{i t}\right)+\beta_{11} \ln \left(I D H m_{i t}\right)+\beta_{12} \ln \left(I Q I M_{i t}\right)+\varepsilon_{i t}
\end{aligned}
$$

Em que: $I Q I M_{i t}$ representa a variável dependente do município i no período t para a equação 4; $\alpha$ representa o vetor de efeitos específicos para cada município; $\beta_{1}$ a $\beta_{12}$ são os parâmetros a serem estimados; GINI $_{i t} ; I D H m_{i t} ;$ PIB $_{\text {per }}$ it são as variáveis explicativas para a equação 4 e $\varepsilon_{\text {it }}$ representa o termo de erro. Todas as variáveis foram transformadas em logaritmo natural para o cálculo das elasticidades; e os índices (IQIM $M_{i t}$; GINI $I_{i t}$;

17 O teste de causalidade de Granger procura determinar o sentido causal entre duas variáveis, estipulando que "X Granger causa Y" se valores passados de X ajudam a prever o valor presente de Y. Para mais detalhes, ver Adams et al. (2003) e Devlin e Hansen (2001). 
$\left.I D H m_{i t}\right)$ para conversão em logaritmo, com escala de 0 a 100 (100\% representando a unidade ou todo). As demais equações (5, 6 e 7), substitui-se a variável dependente IQIM pelas variáveis socioeconômicas do estudo, para analisar o coeficiente qualidade institucional como variável exógena ou explicativa.

Neste modelo geral, o intercepto e os parâmetros resposta são diferentes para cada indivíduo e para cada período de tempo. Existindo, assim, mais parâmetros desconhecidos do que observações, não sendo possível, neste caso, estimar os seus parâmetros.

Nesse sentido, é necessário especificar suposições acerca do modelo geral a fim de torná-lo operacional. Entre os modelos que combinam dados de séries temporais e dados em corte transversal, três são os mais utilizados. São eles: Modelo de Efeitos Fixos e Modelo de Efeitos Aleatórios. Contudo, para um pequeno número de amostra temporal de 2 pontos no tempo (2000 e 2010) e amostral corta transversal maior de 20 municípios existem uma predominância pelo modelo de Efeitos Fixos (via teste de Hausmann).

O modelo de efeitos fixos é a melhor opção para modelar os dados em painel, quando o intercepto, $\alpha_{i}$, é correlacionado com as variáveis explicativas em qualquer período de tempo. Além disso, como o intercepto do modelo é tratado como um parâmetro fixo, também é desejável usar efeitos fixos quando as observações são obtidas de toda a população e o que se deseja fazer são inferências para os indivíduos dos quais dispõe-se de dados.

O modelo de efeitos fixos foi utilizado porque existem variáveis não observadas que provavelmente afetam as variáveis socioeconômicas. Nesse sentido, esse modelo controla as variáveis omitidas da regressão. Além disso, o modelo de efeitos fixos permite um único intercepto para cada município.

\subsection{Base de dados}

No presente trabalho, a investigação utiliza uma amostra de 20 municípios do território de identidade do sisal, para os quais as variáveis necessárias para a estimação do modelo estavam acessíveis. O período de análise é dos anos de 2000 e 2012, que apresentou um conjunto de dados mais completos e consistentes. A seguir será feita a descrição das variáveis, juntamente com a identificação das fontes de dados:

- PIB per capita (PIBperit): representada pela variável renda per capita municipal obtida para o ano de 2010, na base de dados do Instituto de Pesquisa Econômica Aplicada (IPEA, 2015). O nível de renda per capita inicial foi incluído no modelo como referente ao desempenho econômico dos municípios, calculado através da divisão do PIB corrente municipal e o número de indivíduos residentes. 
- Qualidade institucional (IQIMit): a proxy da qualidade institucional foi obtida através da mensuração do Indicador de Qualidade Institucional Municipal (IQIM) do ano de 2012, construído com dados do Perfil de Informações Municipais - MUNIC dos anos de 2009 e 2012, elaborado pelo IBGE (2015), e de dados das Finanças do Brasil - FINBRA, elaborado pela Secretaria do Tesouro Nacional (STN, 2015). Esse índice foi elaborado pelo Ministério do Planejamento, Orçamento e Gestão, sendo disponível apenas para o ano 2000, também utilizado como variável explicativa do modelo (IQIM00). O indicador é resultante da soma dos percentuais iguais $(33,33 \%)$ de três grupos de subindicadores, conforme verificado na Tabela 1.

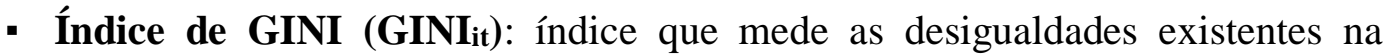
distribuição da renda domiciliar per capita entre os indivíduos. Possui valores variando na escala de 0 a 1 , este último representa a máxima existência de desigualdade, disponibilizados pelo Programa das Nações Unidas para o Desenvolvimento - PNUD (2015).

- Índice de Desenvolvimento Humano Municipal (IDHmit): variável explicativa do nível de desenvolvimento humano dos municípios, partindo de três subindicadores: longevidade, educação e renda, disponibilizados pelo Programa das Nações Unidas para o Desenvolvimento - PNUD (2015).

\section{Resultados e Discussões}

Para analisar a dimensão institucional dos municípios do Território de Identidade do Sisal, utilizou-se de algumas adaptações do Índice de Qualidade Institucional dos Municípios, composto da combinação de três subíndices - grau de participação, capacidade financeira e capacidade gerencial - e cada um teve o mesmo peso $(33,33 \%)$, como mencionado.

Uma vez calculados todos os percentuais dos diferentes subíndices, foi feita uma estratificação dos municípios em agrupamentos homogêneos. É importante ressaltar que o critério utilizado para esse ordenamento foi uma adaptação de estudos que contemplam os aspectos institucionais mais importantes para a administração municipal. Em seguida, foram feitas as correlações entre IQIM e as variáveis que refletem os níveis socioeconômicos dos municípios do Território de Identidade do Sisal. 


\subsection{Análise da dimensão institucional dos municípios sisaleiros}

Para o subíndice Grau de Participação, analisou-se o nível de cidadania dos municípios sisaleiros. Desta forma, este subíndice serviu como uma proxy para o capital social, buscando identificar, por meio da sua existência, o funcionamento e as características dos conselhos municipais e o nível de participação da população nas ações da administração municipal.

Considerando o peso relativo de cada microíndice, já apresentado na seção de metodologia, segue na Tabela 3 a distribuição por faixa percentual do Grau de Participação dos municípios sisaleiros em relação aos 33,33\%.

Verifica-se nível muito baixo da participação da população, tendo os 20 municípios, apresentado nível de condições considerado baixo e regular. Cabe ressaltar que, na maioria das vezes, esses conselhos existem apenas na lei e não ou nunca funcionaram, com exceção dos conselhos de educação, saúde e tutelar, nos quais, basicamente, todos os municípios, inclusive a população, têm interesse maior por conta das transferências de recursos.

Tabela 3 - Distribuição por faixa percentual do Grau de Participação dos municípios sisaleiros, 2012

\begin{tabular}{|c|c|c|c|}
\hline $\begin{array}{l}\text { Faixas em \% do Grau de Participação em relação à } \\
\text { média do Território de Identidade do Sisal }\end{array}$ & $\begin{array}{l}\text { Número de } \\
\text { Municípios }\end{array}$ & $\begin{array}{c}\text { \% de } \\
\text { Municípios }\end{array}$ & $\begin{array}{l}\text { Nível de } \\
\text { Condições }\end{array}$ \\
\hline$<8,33$ & 13 & 65 & Baixo \\
\hline $8,33 \mathrm{a}<16,66$ & 7 & 35 & Regular \\
\hline $16,66 \mathrm{a}<24,99$ & 0 & 0 & Mediano \\
\hline$>24,99$ & 0 & 0 & Alto \\
\hline 33,33 & 20 & 100 & \\
\hline
\end{tabular}

Fonte: Resultados da pesquisa.

Tal caraterística também foi identificada no estudo de Guariente (2010), para os pequenos municípios paulistas de Cajobi, Guaraci e Severínia, em que o autor identificou baixíssima participação popular nos processos de confecção e implementação de importantes documentos públicos. Conforme o autor, o munícipe não consegue respaldarse em compromissos públicos assumidos nos mais diversos instrumentos de planejamento para que assim possa reivindicar aos seus representantes públicos a efetivação de ações que visam a sua qualidade de vida. 
Por essa ótica Guariente (2010), demonstra que essa baixa participação popular em nenhum momento é vista pela maioria dos gestores públicos dos municípios investigados como um problema a ser enfrentado. Tanto que não existe sequer uma visão de que poderiam criar uma política de incentivo à gestão social, em que se ofereceria as condições necessárias para promoção da cidadania e de debates em prol ao desenvolvimento local desejado.

Assim, em relação a outro importante mecanismo contribuinte para o processo construtivo e fiscalizatório do planejamento municipal, os Conselhos Municipais, afirmase que sua existência e funcionamento condiz mais a uma exigência legal do que mesmo a uma postura de que podem ser um meio institucionalizado para o controle social e transparência das ações governamentais.

Desta forma, estes atores sociais podem e devem exercer sua cidadania, auxiliando e exigindo das instituições de fiscalização e dos próprios gestores públicos níveis satisfatórios de transparência governamental em todas as esferas de poder. Assim, além da conquista de uma maior transparência dos atos governamentais, o fortalecimento do accontability ainda pode proporcionar a legitimação do governo frente aos seus representados, à satisfação dos anseios da coletividade e ao fortalecimento das instituições públicas e, portanto, o fortalecimento do Estado Democrático.

O segundo subíndice determinou a Capacidade Financeira dos municípios sisaleiros, e seu cálculo foi feito por intermédio de três microíndices: existência de consórcio (União, Estado e Intermunicipal), receita corrente versus dívida e poupança real per capita. Assim, em relação ao primeiro microíndice, apenas quatro municípios se destacaram, sendo eles: Barrocas, Araci, Serrinha e Teofilândia. Este resultado serviu para mostrar que, mesmo após o decreto 11.107 de 2005, que determina a prática dos Consórcios Públicos, incentivando a cooperação entre municípios, este instrumento ainda não está sendo efetivamente aproveitado com a finalidade de resolver problemas e atender os interesses comuns da sociedade.

O segundo microíndice mediu a relação da dívida do município e suas receitas correntes líquidas. Os resultados mostram que dos 20 municípios, dez apresentaram índice superior à unidade, oito apresentaram índice inferior à unidade e de dois municípios não foi possível obter esta informação, pois, para o ano de 2012, o exercício financeiro dos municípios de Candeal e Queimadas não foi aprovado. Assim, os resultados apontam que metade do total dos municípios do Território de Identidade do Sisal tinha recursos suficientes para quitar suas dívidas, ou seja, a folha de pagamentos e os compromissos já empenhados. Significa dizer que estes dez municípios apresentaram uma boa capacidade de gerir suas finanças públicas. 
O terceiro microíndice da Capacidade Financeira calculou a Poupança Real per capita dos municípios sisaleiros, obtida pela expressão (02). A nota de 1 a 6 foi dada com base no valor do salário mínimo vigente para o ano de 2012. Assim, a nota mínima 1 foi atribuída aos municípios cujo valor obtido estivesse na faixa compreendida entre 0 e $R \$$ 622,00. As demais notas foram atribuídas seguindo a mesma lógica. Nesse sentido, os resultados apontaram que apenas dois municípios, Candeal e Queimadas, obtiveram nota mínima, pois não se obteve informação em relação a suas contas para o ano de 2012. Um município, Conceição do Coité, obteve resultado entre 1 e 2 S.M.; 13 municípios obtiveram resultado entre 2 a 3 S.M.; e quatro municípios obtiveram resultado entre 3 a 4 S.M - Barrocas, Biritinga, Ichu e Nordestina.

A Tabela 4 apresenta de forma geral o subíndice Capacidade Financeira dos municípios sisaleiros, considerando o peso relativo de cada microíndice. A maioria dos municípios, 85\%, está classificada no nível de condição mediano, dois municípios, Candeal e Queimadas, obtiveram percentual considerado baixo e apenas um município alcançou nível de condição considerado alto: Barrocas, com 14.495 habitantes. Em síntese, pode-se dizer que os resultados mostraram que a capacidade financeira dos municípios do Território de Identidade do Sisal obteve desempenho satisfatório, mas evidencia-se que, de forma geral, percebe-se uma carência da capacidade dos municípios de participar de consórcios públicos. Assim, em relação a discussão institucional, a realização de Consórcio Públicos, está diretamente relacionada à ideia de incentivo à cooperação o território do sisal apresenta um padrão mediano.

Tabela 4 - Distribuição por faixa percentual da Capacidade Financeira dos municípios sisaleiros, 2012

\begin{tabular}{|c|c|c|c|}
\hline $\begin{array}{l}\text { Faixas em \% da Capacidade Financeira em relação } \\
\text { à média do Território de Identidade do Sisal }\end{array}$ & $\begin{array}{l}\text { Número de } \\
\text { Municípios }\end{array}$ & $\begin{array}{c}\% \text { de } \\
\text { Municípios }\end{array}$ & $\begin{array}{c}\text { Nível de } \\
\text { Condições }\end{array}$ \\
\hline$<8,33$ & 2 & 10 & Baixo \\
\hline $8,33 \mathrm{a}<16,66$ & 0 & 0 & Regular \\
\hline $16,66 a<24,99$ & 17 & 85 & Mediano \\
\hline$>24,99$ & 1 & 5 & Alto \\
\hline 33,33 & 20 & 100 & \\
\hline
\end{tabular}

Fonte: Resultados da pesquisa.

Em relação à Capacidade Gerencial, o primeiro microíndice avaliou a existência de cadastro imobiliário. Assim, os resultados indicam que todos os 20 municípios apresentam cadastro imobiliário e apenas quatro municípios não têm cadastro imobiliário informatizado. Observou-se também que cinco municípios não têm a planta genérica de valores e quatro municípios não têm a planta genérica de valores informatizada. 
Quanto ao resultado do microíndice cobrança de IPTU, apenas um município não cobra o devido tributo, caso do município de Teofilândia. Cabe destacar que não basta constar a cobrança do IPTU, pois ocorre que, na maioria das vezes, o tributo é caracterizado por ineficiência fiscal, com ausência ou precariedade dos cadastros de imóveis urbanos, principalmente em relação à base de cálculo do tributo. Junto ao desinteresse das autoridades municipais, a consequência disso tudo é um impacto direto na arrecadação.

Os resultados do microíndice que mediu os instrumentos de gestão pública municipal mostram que alguns municípios como Tucano, Araci e Serrinha apresentaram todos os instrumentos analisados. Observou-se que dos 20 municípios, seis apresentaram apenas um instrumento de gestão e sete apresentaram pelo menos dois instrumentos de gestão, mostrando o baixo desempenho dos municípios sisaleiros em relação à existência dos instrumentos de gestão pública. É importante ressaltar que existem vários outros instrumentos importantes, mas foram considerados apenas estes citados neste trabalho, obedecendo à metodologia do IQIM.

Já em relação ao microíndice existência de instrumentos de planejamento, os resultados mostraram que apenas oito municípios não têm Plano Diretor, são eles: Biritinga, Lamarão, Retirolândia, São Domingos, Candeal, Nordestina, Cansanção e Quijingue. Vale destacar que alguns destes municípios têm menos que 20 mil habitantes, sendo assim, estão isentos da obrigatoriedade imposta pelo Estatuto da Cidade, com exceção dos dois últimos. Mas é importante ressaltar também que, apesar de o município não ter tal obrigatoriedade, não significa dizer que não possa ter um instrumento tão valioso de política urbana. Ainda importa registrar que, apesar de alguns municípios não terem leis específicas de instrumentos de gestão apresentadas anteriormente, em alguns casos, eles estão integrados como parte do Plano Diretor.

Ainda sobre o resultado do microíndice que mediu a existência dos instrumentos de planejamento, observou-se que $100 \%$ dos municípios têm tanto Lei Orgânica quanto Plano Plurianual, vigentes para o quadriênio 2010/2013. Assim, fica constatado o bom desempenho do instrumento de planejamento se comparado ao microíndice instrumentos de gestão pública.

A Tabela 5 apresenta a distribuição dos municípios do Território de Identidade do Sisal por faixa em relação aos 33,33\% do subíndice que mede a Capacidade Gerencial. 
Tabela 5 - Distribuição por faixa percentual da Capacidade Gerencial dos municípios sisaleiros, 2012

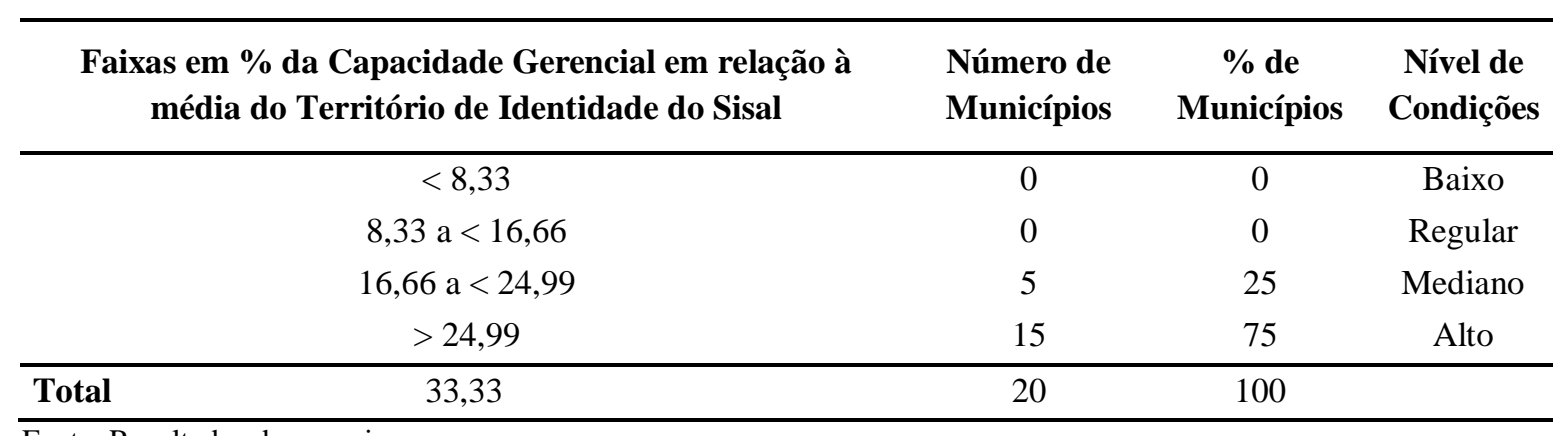

Fonte: Resultados da pesquisa.

Percebe-se que nenhum município sisaleiro foi caracterizado com nível de condição considerado baixo e regular. Do total, cinco municípios têm nível de condição considerado mediano, representando $25 \%$, e 15 municípios sisaleiros estão classificados em um nível de condição considerado alto.

Até o momento, foram apresentados para os municípios do Território de Identidade do Sisal apenas os subíndices que compõem o IQIM, sendo interessante analisar também o valor agregado final do IQIM do Sisal.

\subsection{Análise do Índice de Qualidade Institucional dos Municípios do Sisal}

No ano de 2000, o IQIM foi calculado em nível nacional, utilizando como base de cálculo 5.507 municípios brasileiros. Neste artigo, o objetivo foi tentar recalcular, utilizando dados mais recentes e uma base de cálculo muito menor com apenas 20 municípios para o período de 2012. Contudo, este estudo não tem a intenção de analisar a evolução dos resultados do IQIM de 2000 para 2012. Tal comparação só seria possível caso a metodologia adotada fosse a mesma, uma vez que se utilizou como base de cálculo para o IQIM de 2012 apenas a média do Território de Identidade do Sisal, não a média do Brasil.

Os mapas da Figura 6 mostram os valores em quantis do IQIM para os municípios do Território de Identidade do Sisal nos anos de 2000 e 2012. Inicialmente, deve ser observado que os mapas representam uma proporção acumulada de valores do IQIM do sisal, sendo possível a visualização da quantidade de municípios nas respectivas faixas estabelecidas. 
Figura 6 - IQIM dos municípios sisaleiros, 2000 -2012

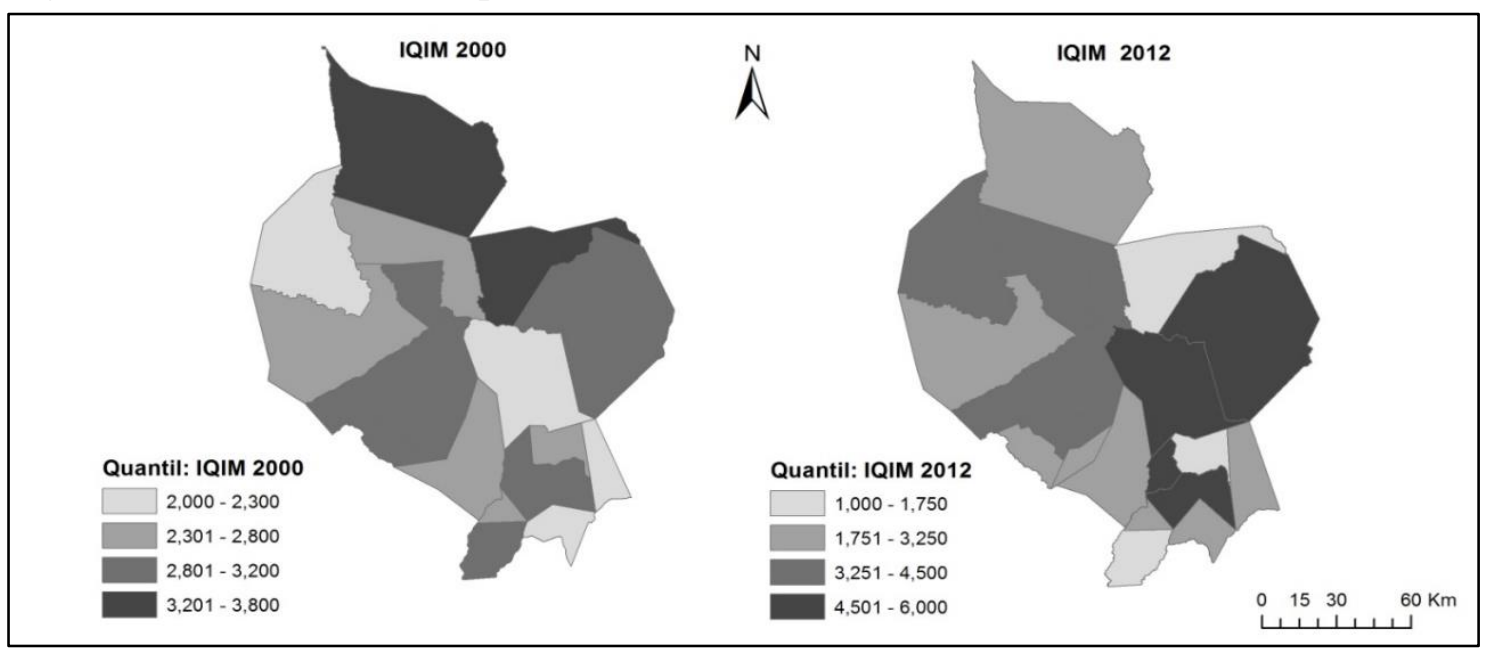

Fonte: Elaborado pelos autores com base no MPOG (2000) e resultados da pesquisa.

Para o ano 2000, por exemplo, percebe-se que os municípios sisaleiros apresentaram valores entre 2,00 e 3,80 em uma escala que vai de 1 a 6 . No geral, os níveis institucionais dos municípios sisaleiros eram considerados baixos neste período. Monte Santo e Quijingue foram os municípios que apresentaram melhores níveis institucionais em 2000; enquanto Araci, Biritinga, Itiúba e Lamarão apresentaram os piores níveis institucionais. A mudança institucional aqui foi analisada pela ótica da transformação das estruturas administrativas de governo - dentro dos processos políticos, guiada de forma não determinante por interesses e desejos gerou uma melhoria local.

Analisando o ano de 2012, os resultados, assim como em 2000, apontam para uma heterogeneidade da qualidade institucional na região. Percebe-se que, entre os 20 municípios, 11 municípios apresentam valores entre as duas primeiras faixas de pior desempenho, enquanto quatro municípios apresentam valores considerados altos (Araci, Barrocas, Serrinha e Tucano).

Para este estudo, a intenção é tentar entender se os níveis institucionais dos municípios sisaleiros se refletem em seus níveis socioeconômicos. A análise da correlação entre qualidade institucional e nível socioeconômico será apresentada na próxima seção.

\subsection{Análise da correlação entre IQIM e variáveis socioeconômicas}

Para fins de análise, foram calculados os coeficientes de correlação de Pearson entre o IQIM e os indicadores socioeconômicos PIB, PIB per capita, índice de Gini e IDH-M para os municípios do Território de Identidade do Sisal. Os índices de Gini e do IDHM foram utilizados para análise dos dados de 2010, último censo do IBGE. Os resultados obtidos são mostrados na Tabela 6. 
Tabela 6 - Coeficiente de Correlação de Pearson com dados de 2000 e 2012

\begin{tabular}{ccc}
\hline Variáveis & Coeficiente de Correlação 2000 & Coeficiente de Correlação 2012 \\
\hline IQIM e PIB & 0,11908794 & 0,58068697 \\
IQIM e PIB per capita & $-0,00526024$ & 0,38492142 \\
IQIM e Gini & 0,01081718 & 0,41078220 \\
IQIM e IDHM & $-0,11416109$ & 0,13237024 \\
\hline
\end{tabular}

Fonte: Elaborado pelos autores.

Os dados analisados revelam correlações lineares positivas entre o IQIM e o PIB 2000 e 2012, respectivamente, $(0,11)$ e $(0,58)$, indicando que as variáveis variam no mesmo sentido. Este resultado reflete a existência de uma relação positiva e crescente ao longo do tempo entre o IQIM e os níveis de riqueza na região. Nos gráficos da Figura 7, visualiza-se a correlação positiva entre IQIM e PIB dos municípios sisaleiros.

Figura 7 - Relação do IQIM com o PIB

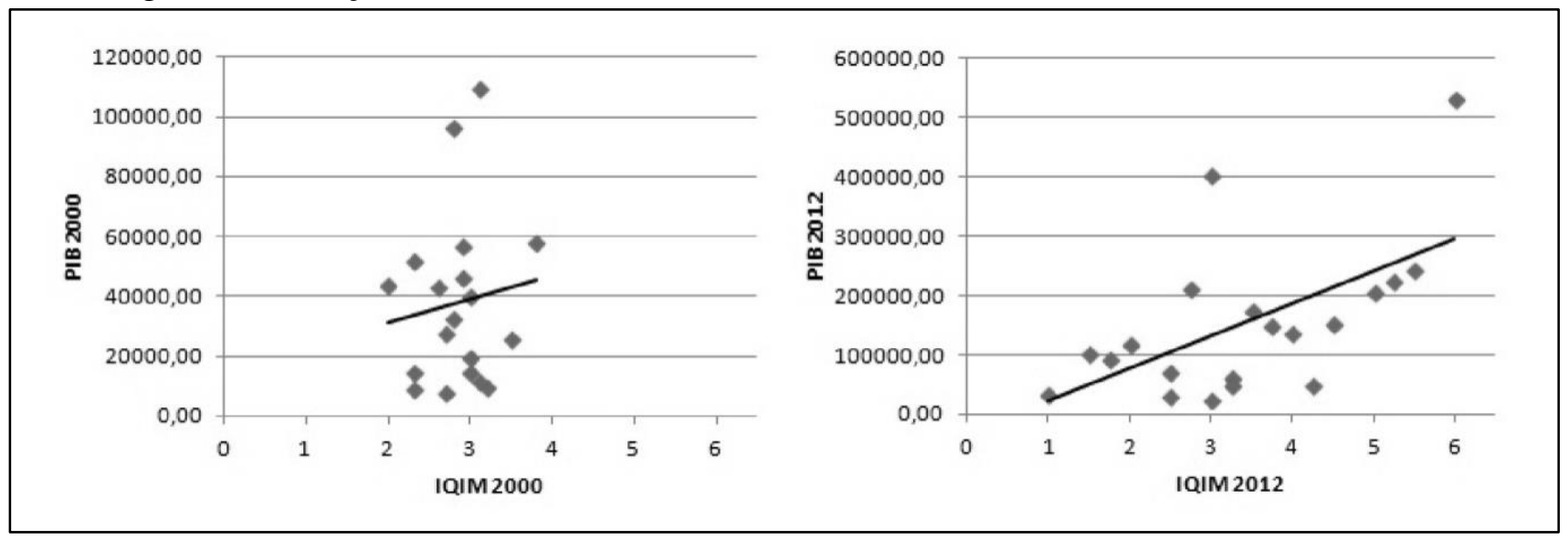

Fonte: Elaborado pelos autores a partir dos resultados da pesquisa

Em relação à correlação entre IQIM e PIB per capita, para o ano de 2000, esta correlação foi negativa, $(-0,005)$, bem próxima do valor zero, conforme gráfico da Figura 8. Contudo, para o ano de 2012, o sentido da correlação se inverte, apresentando uma correlação positiva $(0,38)$.

A literatura admite que, além de as instituições influenciarem os níveis de riqueza na região, o contrário também é admitido. Neste caso, é notório considerar também que tais efeitos podem ser simultâneos. Considera-se, portanto, a existência de endogeneidade entre as variáveis analisadas. 
$\mathrm{Na}$ análise da correlação entre o IQIM e o índice de Gini, embora os resultados tenham apontado valores positivos $(0,01)$ e $(0,41)$ para os anos de 2000 e 2012, respectivamente, a interpretação a ser feita é contrária, uma vez que o índice de Gini é considerado bom quando os valores são próximos de zero. $\mathrm{O}$ mesmo não ocorre quanto à interpretação da correlação entre IQIM e IDHM, já que, neste caso, o IDHM é considerado bom quando seu valor é mais próximo de 1. Percebe-se que em 2000 o valor foi negativo $(-0,11)$, enquanto em 2012 a correlação é fraca, porém positiva $(0,13)$. Os gráficos das Figuras 9 e 10 mostram os resultados das correlações entre IQIM, Gini e IDH-M.

Figura 9 - Relação do IQIM com o GINI

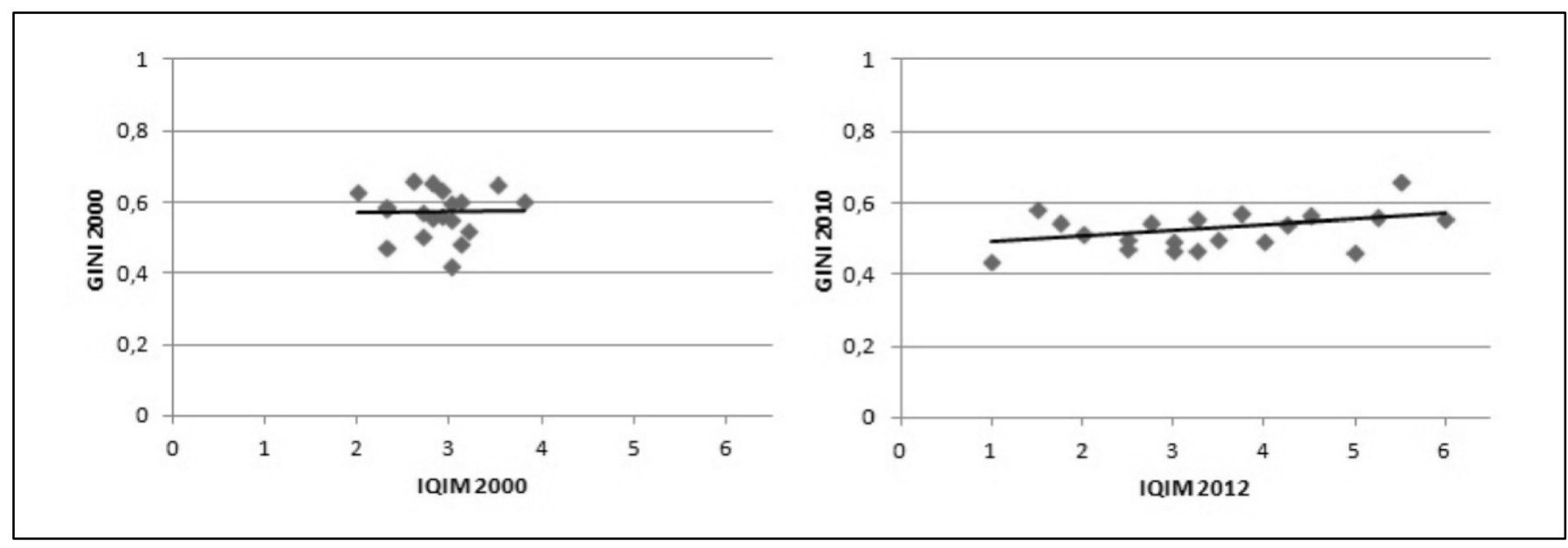

Fonte: Elaborado pelos autores a partir dos resultados da pesquisa.

No geral, os resultados das correlações entre os índices analisados não foram tão expressivos assim. Uma possível explicação é o fato de a região do Sisal compreender municípios em que seus níveis institucionais riqueza e bem-estar não sejam os melhores da Bahia, muito menos do Brasil. Observou-se que, para o ano de 2000, quase não existiu correlação entre as variáveis, uma vez que os resultados atingiram valores bem próximos de zero. Já em 2012, todas as correlações atingiram valores positivos, mesmo os resultados não tenham sido tão expressivos assim, com exceção da correlação entre IQIM e PIB. Portanto, os resultados indicaram relação positiva (moderada) entre qualidade institucional e riqueza, mas não há correlação entre qualidade institucional e distribuição de renda (Gini) e qualidade de vida. 
Figura 10 - Relação do IQIM com o IDHM
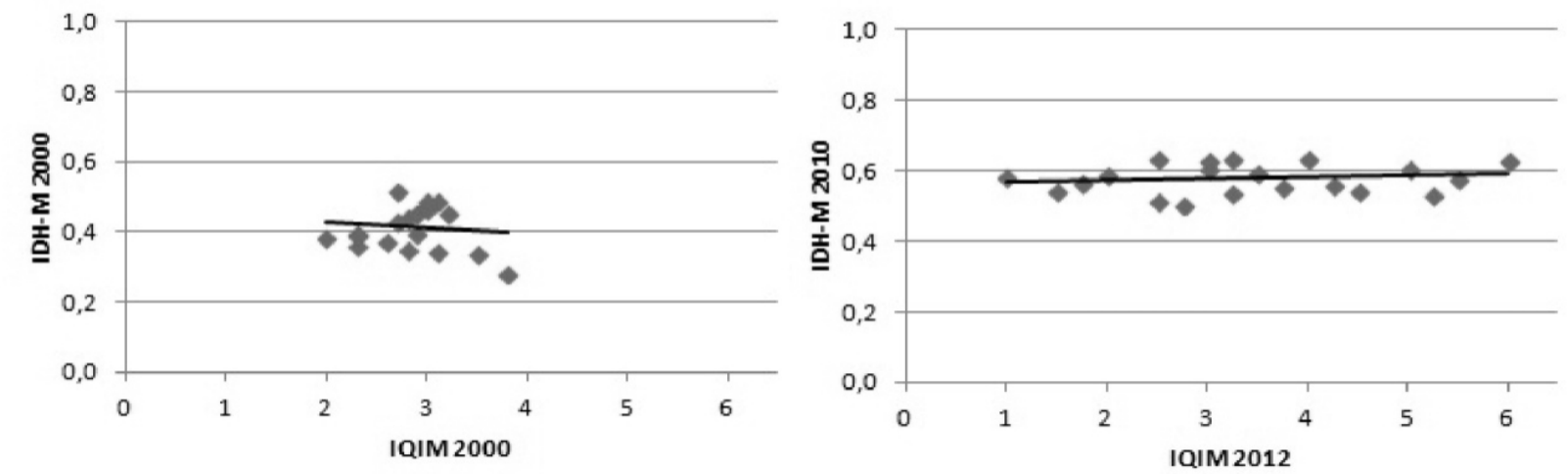

Fonte: Elaborado pelos autores a partir dos resultados da pesquisa.

\subsection{Análise de regressão}

Os resultados apresentados até o momento remetem somente a uma visão pura e isolada dos resultados do IQIM. As análises que serão desenvolvidas nesta seção buscam além de analisar a qualidade institucional, correlacioná-la ao desempenho econômico dos municípios do Território de Identidade do Sisal, representado pelo nível de PIB per capita e ao IDHm e vice-versa, por meio dos modelos de dados em painel. Assim, procurou demonstrar a influência que a qualidade institucional exerce sobre essas variáveis, e os efeitos de um conjunto de variáveis exógenas, através da demonstração dos resultados obtidos na estimação dos parâmetros.

Para os resultados do modelo em dados em painel, a partir dos modelos econométricos (equações 4-7), foram estimados sequencialmente, o modelo de efeitos aleatórios e o modelo de efeitos fixos. Os resultados das estimações e de todos os testes realizados encontram-se na Tabela 7. Logo após a estimação por MQO, realizou-se o teste de heterocedasticidade (Breusch-Pagan/Cook-Weisberg). O resultado, por sua vez, não rejeitou a hipótese nula de homocedasticidade.

Em relação a presença/ausência de efeitos não observados, observa-se que o teste de Breusch-Pagan (BP), realizado posteriormente às estimações do modelo com efeitos aleatórios, foi significativo a 1\%, o qual rejeita-se a hipótese nula de ausência de efeitos não observados. Nesse caso, deve-se considerar que os municípios possuem muitas características peculiares à sua formação e, muitas dessas caracterizações não são observadas e podem variar entre as unidades cross-section (heterogeneidade não observada). Caso esses fatores não observados influenciem e sejam correlacionadas com as variáveis de interesse, os efeitos estimados destas variáveis serão tendenciosos. 
Ressalta-se que os efeitos não observados podem ser modelados por meio dos efeitos fixos ou aleatórios. O teste de Hausman, no qual se rejeitou a hipótese nula de que os efeitos aleatórios são consistentes, apontou que a melhor seleção é a modelagem por efeitos fixos. Da mesma forma, deve-se levar em consideração que o método de estimação por MQO pode apresentar o viés de heterogeneidade e o de variável omitida (CAMERON e TRIVEDI, 2005).

Em seguida realizou-se o teste de Chow no sentido de corroborar a escolha entre o modelo de efeitos fixos e o modelo pooled, feita pelo teste de Hausmann. O teste de Chow, de acordo com Wooldridge (2002), possui as seguintes hipóteses: $\mathrm{H}_{\mathrm{o}}$ : modelo pooled e $\mathrm{H}_{1}$ : modelo de efeitos fixos (irrestrito). Por intermédio do resultado do teste observou-se a rejeição de $\mathrm{H}_{\mathrm{o}}$ e, desta forma, conclui-se que o modelo de efeitos fixos é uma opção apropriada.

Tabela 7 - Resultados das estimações realizadas para os modelos em dados em painel ${ }^{18}$

\begin{tabular}{|c|c|c|c|c|}
\hline & $\begin{array}{c}\text { Equação } 4 \\
\ln \left(I Q I M_{i t}\right)\end{array}$ & $\begin{array}{c}\text { Equação } 5 \\
\ln \left(\text { PIB }_{\text {per }_{i t}}\right)\end{array}$ & $\begin{array}{c}\text { Equação } 6 \\
\ln \left(I D H_{m_{i t}}\right)\end{array}$ & $\begin{array}{l}\text { Equação } 7 \\
\ln \left(G_{I N} I_{i t}\right)\end{array}$ \\
\hline & \multicolumn{4}{|c|}{ Coeficientes } \\
\hline \multirow[t]{2}{*}{$\ln \left(I Q I M_{i t}\right)$} & & $1.475313^{* * *}$ & $0.757328 * * *$ & -0.000397 \\
\hline & & $(6.347562)$ & (15.70169) & $(-0.015540)$ \\
\hline \multirow[t]{2}{*}{$\ln \left(P I B_{\text {per }_{i t}}\right)$} & $0.115093^{* * *}$ & & $0.061916 * * *$ & $-0.039747 * * *$ \\
\hline & $(6.347562)$ & & $(3.138681)$ & $(-6.076949)$ \\
\hline $\ln \left(I D H_{m_{i t}}\right)$ & $\begin{array}{c}0.733961 * * * \\
(15.70169)\end{array}$ & $\begin{array}{c}0.769185 * * * \\
(3.138681)\end{array}$ & & $\begin{array}{c}0.091190 * * * \\
(3.757888)\end{array}$ \\
\hline $\ln \left(G I N I_{i t}\right)$ & $\begin{array}{c}-0.003091 \\
(-0.015540)\end{array}$ & $\begin{array}{c}-3.971774 * * * \\
(-6.076949)\end{array}$ & $\begin{array}{c}0.733510 * * * \\
(3.757888)\end{array}$ & \\
\hline$\alpha$ & $\begin{array}{c}0.022020 \\
(0.027979)\end{array}$ & $\begin{array}{c}15.23043 * * * \\
(5.856863)\end{array}$ & $\begin{array}{c}-2.373981 \\
(-3.038293)\end{array}$ & $\begin{array}{c}3.927238 * * * \\
(115.0307)\end{array}$ \\
\hline$R^{2}$ & 0.930996 & 0.890752 & 0.902429 & 0.179128 \\
\hline Breusch Pagan & $362.780775 * * *$ & $356.818092 * * *$ & $215.310407 * * *$ & $481.994310 * * *$ \\
\hline \multirow{3}{*}{$\begin{array}{l}\text { Teste de Hausman: } \text { chi }^{2}(3) \\
\text { Teste de Heterocedasticidade }{ }^{19} \text { chi }^{2} \text { (1) } \\
\text { Teste Chow }\end{array}$} & $15.571504 * * *$ & $15.417341 * * *$ & $17.221442 * * *$ & 0.677310 \\
\hline & 1.902394 & 2.117159 & 0.989164 & 0.361924 \\
\hline & $43.565967 * * *$ & $42.123809^{* * *}$ & $23.940258 * * *$ & $82.357493 * * *$ \\
\hline
\end{tabular}

Fonte: elaboração própria com base no programa Stata.

Nota: 1) entre parênteses encontram-se as estatísticas t e z (no caso dos efeitos aleatórios); 2) Níveis de significância: ***: Significativo a 1\%; **: Significativo a 5\%; *Significativo a 10\%. 3) A equação 7 foi estimado pelo Panel EGLS (Cross-section random effects), as equações 4 a 6 estimadas pelo Method: Panel Least Squares (fixed effects).

18 Devido a limitação do banco de dados de 20 municípios e 2 pontos temporais, um modelo de equações simultâneas foi inviável devido a limitação dos graus de liberdades. Também não foi identificada dependência espacial pelo teste I de Moran o que impossibilitou uma regressão espacial.

19 (Breusch-Pagan/Cook-eisberg) 
Desse modo, com base nos testes realizados que indicaram a escolha da modelagem por efeitos fixos, serão analisados os resultados do último modelo estimado (Tabela 7), mais especificamente os fatores relacionados Qualidade Institucional nos municípios do território de identidade do Sisal.

A hipótese discutida pelo presente trabalho, e retratada pela literatura institucionalista, de que a qualidade institucional exerce uma influência sobre a variável renda, é representada pelo sinal positivo no coeficiente do parâmetro IQIM, conforme equação 5. Com base na equação 5 verificamos que o coeficiente de elasticidade estimado em 1,475, significando que um aumento de $10 \%$ na qualidade institucional implica no aumento de no PIB per capita dos municípios da região de estudo $14,75 \%$. O teste do pvalor para t-razão, Ho $=0$, foi 0,0000 , o que significa que a elasticidade institucional é diferente de zero com $99 \%$ de probabilidade.

Já para a equação 4, verifica-se que o contrário também ocorre ao analisarmos, o coeficiente de elasticidade-renda estimado em 0,115, significando que um aumento de $10 \%$ no PIB per capita implica no aumento de na qualidade institucional dos municípios da região de estudo $1,15 \%$. O teste do p-valor para t-razão, Ho $=0$, foi 0,0000 , o que significa que a elasticidade institucional é diferente de zero com $99 \%$ de probabilidade.

Esses resultados são semelhantes ao encontrado por Santana e Barreto (2016, 2017), que verificaram que a influência da qualidade institucional sobre a renda é maior do que o contrário, com ambas as direções apresentarem coeficientes positivos.

A variável IDHM apresentou resultado positivo e bastante significativo para explicar a qualidade institucional. Fato que conforme Santana e Barreto (2016, 2017),dá suporte para iniciar uma nova correlação entre essas duas variáveis, visto que esse índice, além da esfera econômica, representada pelo subindicador da renda, engloba a longevidade e o nível de educação dos municípios, permitindo ampliar ainda mais as análises sobre os limites e efeitos da qualidade institucional sobre outros indicadores. Conforme equação 6 verificamos que o coeficiente de elasticidade estimado em 0.7573 , significando que um aumento de $10 \%$ na qualidade institucional implica no aumento de no IDHm dos municípios da região de estudo 7,573\%. O teste do p-valor para t-razão, Ho $=0$, foi 0,0000 , o que significa que a elasticidade institucional é diferente de zero com $99 \%$ de probabilidade.

Já para a equação 4, verifica-se que o contrário também ocorre ao analisarmos, o coeficiente de elasticidade estimado em 0.7339 , significando que um aumento de $10 \%$ no IDHm implica no aumento de na qualidade institucional dos municípios da região de estudo 7,339\%. O teste do p-valor para t-razão, Ho $=0$, foi 0,0000 , o que significa que a elasticidade institucional é diferente de zero com $99 \%$ de probabilidade. 
Resultado semelhante e pontado por Neto e Nakabashi (2011) e Neto, Nakabashi e Sampaio (2013), utilizando o IQIM como proxy para instituições, analisaram os impactos destas e do capital humano no investimento líquido, respectivamente. Os trabalhos chegaram à conclusão de que o nível de capital humano e a qualidade institucional se relacionam positivamente, uma vez que municípios com maiores níveis de capital humano e melhores arranjos institucionais.

Apesar da relação negativa entre o indicador de desigualdade social de GINI como variável explicativa para a qualidade institucional IQIM na equação 4, e o contrário na equação 7 nada se pode afirmar devido ausência de significância estatística em ambas.

Em síntese, os principais resultados obtidos com a verificação empírica remetem à dupla relação positiva entre qualidade institucional e PIB per capita, bem como a forte influência, da variável IDHM sobre ambas, subentendida como uma relação entre qualidade institucional e desenvolvimento socioeconômico. Verificaram-se os efeitos negativos que a variável GINI imprime sobre a qualidade institucional, não tem significância estatística sobre as desigualdades para os municípios da região.

\section{Considerações Finais}

Trazer o contributo da Economia Institucional para o interior da Economia do Desenvolvimento é importante, na medida em que vem reforçar a perspectiva de abordagem do econômico como fenômeno incrustado no conjunto das relações da sociedade, o que, em particular, tem implicações importantes para a análise do mercado e das suas inter-relações com o poder local e as instituições.

A hipótese da existência de uma correlação entre qualidade institucional e o desenvolvimento socioeconômico dos municípios do Território de identidade do Sisal foi satisfatoriamente aceita por esta pesquisa, a partir de uma análise conjunta de diversos fatores abordados ao longo desse artigo. A partir da mensuração do IQIM do ano de 2012 foi possível verificar as deficiências nos instrumentos de participação popular, gestão financeira e gerencial dos municípios brasileiros, conforme os limites utilizados na construção desse indicador. Apesar de caracterizadas como estruturas homogêneas, observou-se que na realidade as primeiras desigualdades entre os municípios surgem no processo de formação e distribuição do poder dentro dessas estruturas, o que demonstra a importância de reaver suas reais necessidades e corrigir as falhas existentes, visando com isso constituir instituições eficazes para promover o desenvolvimento local e minimizar as desigualdades regionais. 
Dentro desta mesma perspectiva, os resultados observados nos quantitativos de municípios, conforme grupos específicos de pontuações do IQIM do ano de 2000 para o ano de 2012, não permitem afirmar, como alto nível de confiança, que ocorreram avanços nesses padrões de maneira generalizada, visto que nem todos os municípios apresentaram, simultaneamente, variações positivas, o que leva a supor que essa melhoria do indicador foi causada por deslocamentos nas posições municipais ao longo das faixas pontuais.

Pela estratificação dos municípios do Território de Identidade do Sisal em agrupamentos homogêneos para todos os três subíndices que compõem o IQIM, foi possível verificar quais municípios têm melhores e piores níveis de gestão e estrutura administrativa.

Em relação ao Grau de Participação da sociedade nas ações e à tomada de decisão da administração municipal, verificou-se um nível fraco, uma vez que todos os municípios sisaleiros apresentaram um grau baixo de participação. Cabe lembrar que essa realidade está presente na grande maioria dos municípios brasileiros, em que a existência de conselhos municipais só não basta, é preciso, portanto, que as pessoas tomem consciência de que os conselhos são importantes instrumentos e que não devem ser apenas uma realidade jurídico-formal.

Com relação à Capacidade Financeira dos municípios sisaleiros, boa parte deles tinha, em 2012, recursos suficientes para arcar com seus compromissos municipais. Porém, esta mesma lógica não se verifica em relação à capacidade de participar de consórcios públicos, principalmente os intermunicipais, assim como no seu controle na geração de poupança real per capita.

Quanto à Capacidade Gerencial, conclui-se que os municípios sisaleiros apresentam um desempenho satisfatório, comprovado pela presença de instrumentos de gestão e planejamento para gerir e planejar seus recursos.

Contudo, com base na literatura acerca dos determinantes da qualidade institucional de Haddad (2004), esse resultado está ligado ao fato de a região do sisal ter baixo nível de renda per capita e fraca distribuição de renda, fatores que influenciam e são influenciados pela qualidade institucional. Sendo assim, os municípios do Território de Identidade do Sisal podem ser enquadrados como regiões economicamente deprimidas.

Há necessidade de novas visões acerca dos indicadores existentes, ou mesmo que sejam criados novos indicadores que expressem visões completamente diferentes da mesma realidade, para que os agentes que necessitam tomar decisões políticas estejam cercados de opções e, mesmo com a existência de diversas possibilidades, encontrem a metodologia mais eficaz na expressão da realidade em questão. Assim como pesquisas 
medicinais, as pesquisas referentes aos indicadores poderão curar o país dos males que o atingem como a desigualdade social ou a deficiência dos serviços públicos.

Conhecendo melhor estes municípios de pequena concentração populacional, poderão ser utilizados dados e informações capazes de melhorar a capacidade administrativa de seus governos, como também de seus próprios agentes de desenvolvimento local. Com um respaldo técnico-científico fidedigno às suas realidades, estes agentes terão maiores possibilidades de sucesso durante os processos de formulação, implementação e avaliação de políticas públicas.

A presente pesquisa buscou, ainda, ressaltar da utilização de métodos estatísticos para a análise das mais diversas instituições auxiliando no seu processo decisório. Por meio da apresentação dos principais aspectos metodológicos dos dados em painel, esse artigo apresentou novas informações acerca do tema, para que futuras pesquisas empíricas possam ser realizadas.

Pode-se afirmar que existe uma relação direta entre a qualidade institucional e o desenvolvimento socioeconômico, os resultados obtidos pelos modelos de dados em painel apontaram relação positiva entre a qualidade institucional e o PIB e IDHm dos municípios sisaleiros. Os resultados indicam que municípios com maiores IQIM são os que apresentam maiores valores de PIB per capita e IDHm e vice-versa. O que indica uma relação entre os indicadores de bem-estar/qualidade de vida e a qualidade institucional dos municípios. Com o emprego desta metodologia, foi possível verificar que a influência da qualidade institucional sobre a renda é maior que o efeito da renda sobre a qualidade institucional, mas ambas apresentam coeficientes positivos no modelo.

A adoção dos modelos de dados em painel oferece respaldos estatísticos e econométricos para a pesquisa científica transmitindo maior credibilidade aos possíveis trabalhos desenvolvidos, pelo seu maior rigor metodológico. Todavia, é necessário julgar ponderadamente cada situação uma vez que as regressões em dados em painel, apesar apresentam uma série de vantagens na pesquisa aplicada não são adequadas a qualquer situação.

A utilização de técnicas estatísticas oferece informações adicionais ao mercado e a academia anteriormente não aproveitadas, auxiliando pesquisadores, gestores e investidores para controle dos riscos a que estão sujeitos e para seus processos de decisórios e em suas pesquisas. Além disso, este artigo é também uma possibilidade de contribuição importante para a literatura institucionalista na medida em que fornece subsídio para trabalhos empíricos futuros, especialmente estimações econométricas que busquem relacionar qualidade institucional e desenvolvimento econômico. 
Por fim, apesar de algumas limitações a respeito dos dados utilizados, e pelo fato também do próprio IQIM ser um índice que agrega um número razoável de variáveis institucionais, na medida em que fornece subsídio para trabalhos empíricos futuros, especialmente estimações econométricas que busquem relacionar qualidade institucional e desenvolvimento econômico. Visto que o campo de estudo da economia institucional possui caminhos ainda pouco explorados, que permitem a realização de uma gama de pesquisas, que enriquecerão e difundirão o conhecimento sobre o papel desempenhado pelas instituições. Além disso, o ambiente da desigualdade no Brasil possui lacunas que vão além das diferenças de renda, permitindo mergulhar a fundo na identificação das causas e na busca por futuras soluções para esse problema.

\section{Referencial Bibliográfico}

ACEMOGLU, D.; JOHNSON, S.; ROBINSON, J. The Colonial Origins of Comparative Development: An Empirical Investigation. American Economic Review, v. 91, p. 1369-1401, 2001.

ADAMS, P.; HURD, M. D.; McFADDEN, D.; MERRILL, A.; RIBEIRO T. Healthy, Wealthy and Wise? Tests for Direct Causal Paths between Health and Socioeconomic Status. Journal of Econometrics, v. 112, n. 1, p. 3-56. 2003.

BASTOS, S. Q. A.; OLIVEIRA, A. M.H.; RIBEIRO, H. M. D. F. Indicador de Desenvolvimento Institucional Municipal: Impactos sobre a Economia dos Municípios Brasileiros. In: $46^{\circ}$ Encontro Nacional de Economia - ANPEC, 2018, Rio de Janeiro. 2018.

BALTAGI, B. H. Econometrics analysis of panel data. 2 ed. Chichester, UK: Wiley \& Sons, 2001.

BOISIER, S. Conversaciones sociales y dessarollo regional. Editorial de la Universidad de Talca, 2000.

CAMERON, A. C., TRIVEDI, P. K. Microeconomics: Methods and Applications. Cambridge: Cambridge University Press, 2005.

CONAB. Companhia Nacional de Abastecimento. Proposta de Preços Mínimos- Safra 2013/2014 - Produtos de Inverno, regionais e leite. Superintendência de Gestão da Oferta - SUGOF, janeiro de 2013.

CONDER. Companhia de Desenvolvimento Urbano do Estado da Bahia. Base de Dados. Sistema de informações institucionais, 2010.

DEVLIN, N.; HANSEN, P. Health Care Spending and Economic Output: Granger Causality, Applied Economics Letters, v. 8, p. 561-64, 2001.

FIGUEIREDO FILHO, D. B. SILVA JUNIOR, J. A. Desvendando os Mistérios do Coeficiente de Correlação de Pearson (r). Revista Política Hoje, Vol. 18, n. 1, 2009.

GUARIENTE, R. V. Capacidades institucionais de pequenos municípios paulistas: problemas e desafios encontrados na gestão local de Cajobi, Guaraci e Severínia. In: III Congresso Consad de Gestão Pública, 2010, Brasília. III Congresso Consad de Gestão Pública, 2010. 
HADDAD, P. R. Força e Fraqueza dos municípios de Minas Gerais. Cadernos BDMG. Belo Horizonte, MG. n.8 abril de 2004. 84p.

HALL, R. E. \& JONES, C. I. Why do some countries produce so much more output per worker than others? Quarterly Journal of Economics, 114(1):83-116. 1999.

HSIAO, C.. Analysis of panel data. 2 ed. Nova York: Cambridge University Press, 2. Ed. 2003. $359 \mathrm{p}$.

IBGE. Instituto Brasileiro de Geografia e Estatística. Censos Demográficos 2000 e 2010. Ministério da Saúde.DATASUS - Tecnologia da Informação a serviço do SUS.Disponível em: $<$ http://www2.datasus.gov.br/DATASUS/index.php?area=0206>. Acesso em: 25 de maio de 2015.

Instituto Brasileiro de Geografia e Estatística. Produto Interno Bruto dos municípios 2000-2012. Rio de janeiro, 2015.

Instituto Brasileiro de Geografia e Estatística - IBGE. Pesquisa de Informações Básicas Municipais - Perfil dos Municípios Brasileiros. Rio de Janeiro: Instituto Brasileiro de Geografia e Estatística, 2011.

Instituto Brasileiro de Geografia e Estatística - IBGE. Pesquisa de Informações Básicas Municipais - Perfil dos Municípios Brasileiros. Rio de Janeiro: Instituto Brasileiro de Geografia e Estatística, 2012.

IPEA. Instituto de Pesquisa Econômica Aplicada. Banco de dados: IPEADATA. Disponível em: $<$ http://www.ipeadata.gov.br/>. Acesso em: 28 ago. 2015.

KNACK, Stephen; KEEFER, Philip. Institutions and economic performance: cross-country tests using alternative institutional measures. Economics \& Politics, v. 7, n. 3, p. 207-227, 1995.

LEIVAS, P. H. S.; MENEZES, G. R.; CRAVO, T. A.; SANTOS, A. M. A. A geografia das instituições: uma abordagem espacial para os municípios brasileiros. Revista Brasileira de Estudos Regionais e Urbanos, v. 9, n. 2, p. 169-185, 2016.

MARTINS, G.A.M. Estatística geral e aplicada.2.ed, São Paulo, Atlas, 2002. 417p.

MPOG. Ministério do Planejamento, Orçamento e Gestão. Base de dados institucionais dos municípios brasileiros. 2000.

NETO, G. S.B.; NAKABASHI, L. Relações entre instituições, capital humano e acumulação de capital físico nos municípios brasileiros. Economia \& Tecnologia (UFPR), v. 25, p. 131-140, 2011.

NETO, G. S.B.; NAKABASHI, L.; SAMPAIO, A. V. Determinantes do Capital Físico: o papel do capital humano e da qualidade institucional. In: $41^{\circ}$ ENCONTRO NACIONAL DE ECONOMIA, 2013, Foz do Iguaçu - PR. 41 ${ }^{\circ}$ ENCONTRO NACIONAL DE ECONOMIA, 2013.

NORTH, D. Institutions, Institutional Change and Economic Performance. Nova York: Cambridge University Press, 1990.

OLIVEIRA, V.; MENEZEA-FILHO, N.; KOMATSU, B. A Relação entre a Qualidade da Gestão Municipal e o Desempenho Educacional no Brasil. INSPER - Policy Paper. nº 34 agosto, 2018.

PANDE, Rohini; UDRY, Christopher R. Institutions and development: A view from below. 2005.

PEREIRA, A. E. G.; NAKABASHI, L.; SALVATO, M. A. Instituições e nível de renda: uma abordagem empírica para os municípios paranaenses. Nova Economia. Belo Horizonte, MG, 2012. 
PIACENTI, C. A. Indicadores de desenvolvimento endógeno. In: PIACENTI, C. A.; LIMA, J. F. de. (Org.). Análise Regional: metodologias e indicadores. Curitiba, PR: Camões, 2012. 134 p.

O potencial de desenvolvimento endógeno dos municípios paranaenses. Tese (doutorado) - Universidade Federal de Viçosa, Programa de Pós-Graduação em Economia Aplicada. Viçosa, MG. 2009, 201f. Disponível em<http://www.tede.ufv.br/tedesimplificado/tde_arquivos/5/TDE-2010-06-09T121602Z2267/Publico/texto\%20completo.pdf>. Acesso em: 20 de maio 2014.

PNUD. Programa das Nações Unidas para o Desenvolvimento. Atlas do Desenvolvimento $\begin{array}{llll}\text { Humano no } & \text { Brasil 2013. Disponível }\end{array}$ em:<http://www.pnud.org.br/IDH/Default.aspx?indiceAccordion=1\&li=li_AtlasMunicipios $>$.

Acesso em: 20 de maio de 2015.

RIBEIRO, H. M. D.; BASTOS, S. Q. A.; OLIVEIRA, A. M. H. C. Arranjos institucionais e desenvolvimento: uma análise multivariada e espacial para municípios de Minas Gerais. Análise Econômica, v. 35, n. 68, p. 231-262, 2017

SANTANA, A. S.; BARRETO, R. C. S. Qualidade Institucional e Desempenho Econômico: análise empírica dos municípios brasileiros, 2010. Revista Brasileira de Estudos Regionais e Urbanos, v. 10, p. 253-271, 2016.

SANTANA, A. S.; BARRETO, R. C. S. Análisis Descriptivo y Econometrico del indicador de Calidade Institucional de los Municipios Brasileños. COMPENDIUM, v. 4, p. 53-83, 2017.

SANTINI, G. A. OLIVEIRA, S. C. de. PIGATTO, G. Análise da Relação das variáveis preço e produção da mandioca tipo indústria no estado de São Paulo, 1996 a 2008. Informações Econômicas, SP, v40, n.3, mar.2010.

STN. Secretaria do Tesouro Nacional. Finanças do Brasil (FINBRA) - Dados Contábeis dos Municípios. Disponível em: <http://www.tesouro.fazenda.gov.br/contas-anuais>. Acesso em: 02 de out 2015.

TCM. Tribunal de Contas dos Municípios. Prestação de Contas dos Municípios Baianos. 2012. Disponível em: <http://www.tcm.ba.gov.br/tcm/contas.shtml>. Acesso em: 02 de out 2014.

WOOLDRIDGE, J. Econometric analysis of cross section and panel data. Cambridge. Mass: MIT Press, 2002. 


\section{Anexo I - Teste de causalidade Granger}

In(IQIM)-qualidade Institucional não causa (no sentido de Granger) $\ln ($ GINI)-desigualdade

$\ln$ (GINI)-desigualdade não causa (no sentido de Granger) $\ln (\mathbf{I Q I M})$ qualidade Institucional

In(PIB per)-renda per capita não causa (no sentido de Granger) $\ln (\mathbf{I Q I M})$ qualidade Institucional

$\ln (\mathbf{I Q I M})$-qualidade Institucional não causa (no sentido de Granger) $\ln (\mathbf{P I B}$ per)-renda per capita

In(IDHM)-desenvolvimento social não causa (no sentido de Granger) $235.199 \quad 0,7488$ $\ln (\mathbf{I Q I M})$-qualidade Institucional

In(IQIM)-qualidade Institucional não causa (no sentido de Granger) 7.920380 .0054 $\ln ($ IDHM)-desenvolvimento social

\begin{tabular}{l|l|l}
1.28142 & 0.2590 & \\
0.21232 & 0.6455 & não \\
& não
\end{tabular}

In(IDHM)-desenvolvimento social não causa (no sentido de Granger) 0.263000 .6086 $\ln ($ GINI)-desigualdade

In(GINI)-desigualdade não causa (no sentido de Granger) $\ln ($ IDHM)- 46.4495 1.E-10 desenvolvimento social

$\ln (\mathbf{I D H M})$-desenvolvimento social não causa (no sentido de Granger) $\ln (\mathbf{P I B}$ per)-renda per capita

$\ln$ (PIB per)-renda per capita não causa (no sentido de Granger) $\ln ($ IDHM) desenvolvimento social

$\ln (\mathbf{P I B}$ per)-renda per capita não causa (no sentido de Granger) $\ln (\mathbf{G I N I})$ desigualdade

$\ln$ (GINI)-desigualdade não causa (no sentido de Granger) $\ln$ (PIB per)-renda 